[Aus dem hygienischen Institut der Universität Halle a/S.]

(Direetor: Geheimrath Prof. Dr. C. Fraenkel.)

\title{
Die Pneumokokken.
}

\section{Vergleichende}

Untersuchungen mit besonderer Berücksichtigung der Agglatination.

$$
\text { Von }
$$

\section{Amy Kindborg, M.D.}

Unsere fortschreitende Kenntniss der Balkterien hat es mit sich gebracht, dass manche Begriffe, unter denen man früher eine einzige Bakterienart verstand, insofern eine Aenderung erfahren haben, als wir jetzt an deren Stelle eine Vielheit zwar nahe mit einander verwandter und in wesentlichen Eigenschaften übereinstimmender, unter sich jedoch Unterschiede aufweisender Bakterien zu setzen gelernt haben. Dies gilt ganz besonders von den Bakterien der Typhus- und Coli-Gruppe, von den Tubereuloseeregern und von den Eiterkokken. Man ist jedoch in diesen Bestrebungen noch weiter gegangen und hat versucht, selbst einen scheinbar so scharf umschriebenen und eng begrenzten Begriff, wie den des Fränkel-Weichselbaum'schen Pneumococcus in eine Reihe von Unterarten aufzulösen. Es ist dies eine zweite und gewissermaassen rückläufige Phase in der Entwickelung der Lehre rom Pneumococeus, denn ursprünglich war man zu der Aufstellung dieses Begriffs dadurch gelangt, dass man die im Speichel normaler Personen und im Bronchialsecret Pneumoniekranker vorkommenden Diplokokken, auf Grund der Erkenntniss ihrer gemeinsamen Eigenschaft, bei Versuchsthieren Septicämie zu erregen, zu einer Art vereinigt hatte.

Der Erste, der diese beiden mit einander verglich, war A. Fränkel ${ }^{1}$;

1 A. Fränkel, Verhandlungen des III. Congresses für innere Medicin. 1884. Zeitschrift für klin. Medicin. 1886. Bd. X. 
vor ihm hatten schon Friedländer ${ }^{1}$ und auch andere Forscher einen kokkenähnlichen Mikroorganismus aus pneumonischem Sputum beschrieben, von welchem jetzt noch eine Bakterienart unter dem Namen des Pneumo bacillus Friedländer als Erreger mancher Pneumoniefälle anerkannt wird, mit dem eigentlichen Pneumococcus jedoch nichts zu thun hat.

Die grundlegenden Untersuchungen über die Erreger der mensehlichen Pneumonie stammen aus dem Jahre 1886 von A. Weichselbaum ${ }^{2}$, der ausser dem eben erwähnten Friedländer'schen Organismus, hauptsächlich den Fränkel'schen Diplococcus in entsprechenden Krankheitsfällen gefunden hat; daneben fand er auch Streptokokken, von denen es nach unserer jetzigen Kenntniss dahingestellt bleiben mag, ob es sich um wirkliche Streptokokken (in Fällen ron septischer Pneumonie) oder nicht etwa um streptokokkenähnliche Varietäten der Pneumokokken gehandelt hat. - Schon im folgenden Jahre wurde die Weichselbaum'sche Entdeckung des Diplococcus Pneumoniae von Gamaleĩa ${ }^{3}$ und Anderen bestätigt. Um die Erforschung der septicämieeregenden Miliroorganismen des Speichels hat sich besonders Sternberg ${ }^{4}$, ferner auch Biondi ${ }^{5}$ bemüht, welch' Letzterer einen solchen unter dem Namen Bacillus Salivarius Septicus im Jahre 1887 beschreibt und auch schon der Ansicht huldigt, dass derselbe mit den ron Fränkel und Weichselbaum gefundenen Pneumonieerregern identisch sei. Von dem Vorkommen streptokokkenähnlicher Varietäten des Pneumococcus sprechen bereits einige Jahre nach dessen Entdeckung $\mathrm{Banti}{ }^{\text {B, }}$, der vier Arten hauptsïchlich nach der Kettenbildung unterscheidet, und vor Allem Kruse und Pansini ${ }^{7}$, die mit einem sehr grossen Material von Pneumoniestämmen gearbeitet haben. Auch Fo $\dot{a}^{8}$, der nach anderen Gesichtspunkten mehrere Varietäten des Pneumococcus unterscheidet, bezeichnet eine dieser Varietäten als Streptococcus lanceolatus. Artenunterschiede machen ausserdem Eyre und Washbourn ${ }^{9}$, und zwar nach der Virulenz und der Widerstandsfähigkeit der betreffenden Stämme. Lery und Steinmetz ${ }^{10}$ beschreiben auch mehrere

${ }^{1}$ Friedländer, Virchow's Archiv. Bd.LXXXVII. - Fortschritte der" Med. Bd. I. Nr. 22. S. 287.

${ }^{2}$ A. Weichselbaum, Medicin. Jahrbücher. Wien 1886. - Monatsschrift für Ohrenheilkunde. 1888. Nr. 8 u. 9. - Centralblatt für Bakteriologie. 1883. Bd. V.

${ }^{3}$ Gamaleïa, Annales de l'Institut Pasteur. T. II. p. 440.

${ }^{4}$ Sternberg, Ref. in Centralblatt für klin. Medicin. 1885.

5 Biondi, Diese Zeitschrift. 1887. Bd. II. S. 199.

- Banti, Archivia di anatom. norm. e pathol. Firense 1890.

7 Kruse und Pansini, Diese Zeitschrift. 1892. Bd. XI., S. 279.

8 Foà, Ebenda. 1893. Bd. XV. S. 369.

- Eyre aud Washbourn, Lancet. Vol. I. p. 19.

${ }^{10}$ Levy und Steinmetz, Archiv für experim. Pathologie. Bd. XXXVII. S. 89. 
A barten, meinen aber, dass diese in einander übergeführt werden können, und in ähnlichem Sinne äussert sich Stoltz. ${ }^{1}$ - Als dann mit der Entdeckung des Agglutinationsphänomens durch Gruber und Widal eine neue Untersuchungsmethode in die Bakteriologie eingeführt wurde, hat dieselbe auch auf den Pneumococcus Anwendung gefunden. Dabei stellte es sich dann heraus, dass bei Fällen von menschlicher Pneumonie die agglutinirende Wirkung des von dem Kranken gewonnenen Serums sich gegenüber den von demselben Falle isolirten Pneumokokken deutlicher zeigte als gegenüber Anderen (Gargano und Fattori ${ }^{2}$ ), und dass es sogar Fälle gab, in denen eine Agglutination überhaupt nur mit demselben Stamme zu erreichen war. Bezançon und Griffon ${ }^{3}$, die die letztere Erscheinung beobachtet haben, sahen sich daher zu der Vermuthung veranlasst, dass man sich möglicher Weise des Agglutinationsverfahrens zur Unterscheidung verschiedener Rassen des Pneumokokkus bedienen könne. Anderweitige Aeusserungen über die Benutzung der Agglutinationsmethode zur Unterscheidung verschiedener Pneumococcenarten habe ich in der mir zugänglichen Litteratur nicht finden künnen. Dagegen haben Eyre und Washbourn ${ }^{4}$ festgestellt, dass sich auch die immunisirenden Eigenschaften des Serums nicht gleichmässig gegen alle Pneumokokkenstämme richteten, und sind daher der Meinung, dass ein specifisches Immunserum ein Mittel sei, um mehrere Rassen des typischen Pneumococcus unterscheiden zu lassen. In ähnlichem Sinne äussert sich Foà, welcher die vẹrschiedenen und einander widersprechenden Ergebnisse der Autoren bei Immunisierungsversuchen mit Pneumokoklken darauf bezieht, dass die Untersucher verschiedene Varietäten dieses Mikroorganismus vor sich hatten. Diese Schlussfolgerungen sind indessen, wie man sieht, bisher immer nur aus vereinzelten und zufälligen Befunden gezogen worden, während systematische Untersuchungen darüber bislang noch nicht vorlagen, so dass Weichselbaum in seinem Aufsatz über den Pneumococeus im Handbuch von Kolle-Wassermann eine weitere Bearbeitung dieser Gebiete in dem gedachten Sinne als wünschenswerth hinstellt.

Ich bin daher gern einer Aufforderung Herrn Prof. Fränkel's gefolgt, solche Untersuchungen an einem grösseren Material von eigens zu diesem Zwecke isolirten Pneumokokkenstämmen vorzunehmen, nicht ohne dieses Material zugleich auch noch von anderen Gesichtspunkten aus zu bearbeiten.

${ }^{1}$ Stoltz, Centralblatt für Bakteriologie. Abth. I. Bd. XXIV. S. 387.

${ }^{2}$ Gargano e Fattori, Rivista critica di clinica medica. 1903. Nr. 12-15.

${ }^{8}$ Bezançon et Griffon, Soc. de Biol. Juin 5. - Semaine méd. p. 217.

${ }^{4}$ Eyre and Washbourn, Brit. med. Journ. Vol. II. p. 124. 
Bei meinen Untersuchungen ging ich in der Weise ror, dass ich mir eine grössere Anzahl von Pneumokokkenstämmen aus verschiedenen Quellen (normalem Speichel, pneumonischem Sputum, Empyem u. s. w.) isolirte und diese zunächst in ihrem morphologischen und culturellen Verhalten, später in ihren Beziehungen zum Serum mit einander verglich. Dabei sei des besseren Verständnisses wegen von vornherein bemerkt, dass ich unter der Bezeichnung "Stamm" stets die Fortzüchtung eines einzelnen und genau in seinen Eigenschaften bestimmten Pneumococcus, unter "Art" oder "Rasse" eine Mehrzahl verschiedener in gewissen maassgebenden Eigenschaften übereinstimmender Bakterien der genannten Typen verstehe. Dass die einzelnen ron mir isolirten Stämme während der ganzen Dauer der Untersuchungen streng aus einander gehalten werden, bedarf eigentlich nicht der ausdrücklichen Erwähnung.

Solcher Stämme wurden im Ganzen 24 isoliert und zwar:

\begin{tabular}{c|c|c} 
Speichelkokken & Pneumonisches Sputum & Tuberculöses Sputum \\
5 Stämme. & 7 Stämme. & enthaltd. Pneumokokken \\
Otitis media-Eiter & Empyemeiter & 4 Stämme. \\
2 Stämme. & 2 Stämme. & Panophthalmitis \\
Meningitis & Abscess aù dem Gehirn & 1 Stamm. \\
2 Stämme. & 1 Stamm. &
\end{tabular}

Bevor wir auf die Besprechung dieser Stämme eingehen, mögen erst einige Worte über die

\section{Methodik ihrer Gewinnung und Erhaltung} gesagt sein.

Als der beste Weg zur Cultivirung eines Pneumococcus aus irgend einem Material, in dem man sich von seiner Anwesenheit durch Ausstrichpräparat überzeugt hat, ist die directe intraperitoneale Impfung von Mäusen, welche von allen Versuchsthieren am meisten für diesen Mikroorganismus empfänglich sind - falls derselbe nicht seine Virulenz völlig eingebüsst hat, was bei Material aus Empyem oder alten Abscessen zuweilen vorkommt - und nach der Impfung in 10 bis 24 Stunden zu Grunde gehen. Die zu diesem Zweck nöthige Menge des Materials beträgt bei Sputum höchstens $1 / 2 \mathrm{cem}$. Man findet dann, falls man ein noch zahlreiche andere Bakterien enthaltendes Material, wie z. B. Sputum eingespritzt hat, eine blutig-eitrige Masse in der Bauchhöhle, die verschiedene Bakterienarten enthält, wohingegen im Herzblut der mit eingebrachte Pneumococcus sich in Reincultur vorfindet. Man bedient sich also am besten des Herzblutes 
sofort nach Eröffnung des Thieres unter sorgfältiger Vermeidung der Bauchhöhle zur Anlegung von Culturen, von denen man selbst dann positiven Ausfall erwarten darf, wenn es bei mikroskopischer Durchsicht des Herzblutes nicht gelingt, Pneumokokken aufzufinden. War die intraperitoneale Impfung mit einer Reincultur des Pneumococcus erfolgt, was zu einer nicht-eitrigen, sondern meistens blutig-serösen Ausschwitzung in der Bauchböhle führt, so ist auch diese Flüssigkeit und ebenso der Milzsaft zur Anlegung von Culturen geeignet.

Weniger vortheilhaft als die im Vorstehenden aus einander gesetzte Methode, jedoch bei einiger Uebung ebenfalls ausführbar, ist die directe Isolierung der Pneumokokken aus dem zu untersuchenden Material. Dieselbe erfolgt entweder in der üblichen Weise auf Platten, wobei man es jedoch nicht mit drei Platten, wie es sonst wohl angängig ist, bewenden lassen darf, sondern besser vier oder fünf solche anlegt, um die Pneumokokkencolonieen ganz gesondert zu erhalten und vor der Ueberwucherung durch andere Bakterienarten, der sie sehr leicht ausgesetzt sind, zu schützen. Noch einfacher ist es, sich hierzu der Methode des auf einander folgenden Ausstrichs auf 4 bis 5 Röhrchen mit geeignetem Nährboden zu bedienen. Ueber die in Betracht kommenden Nährmedien, sowie über das Aussehen der Culturen siehe den diesen Dingen besonders gewidmeten Abschnitt. In den meisten Fällen wurde von mir sowohl die Methode der Isolierung des Pneumococcus mit diesem Verfahreu als die seiner Gewinnung mittels des Thierversuches angewandt, worauf ich mich jedes Mal von der Identität der beiden so gewonnenen Pneumokokken überzeugte. Die Isolierung des Pneumococcus unter Ausschluss des Thierkörpers hat indessen den ausserordentlichen Nachtheil, dass hierbei das betreffende Bacterium meist seine Virulenz vollständig einbüsst und damit für die weiteren Untersuchungen verloren ist. Denn bekanntlich ist der Pneumococeus ein Organismus, der sehr dazu neigt, seine Virulenz und mit dieser auch seine Cultivirbarkeit zu verlieren. Es ist daher, um einen Pneumokokkenstamm überhaupt am Leben zu erhalten, nöthig, dass er erst durch Thierpassage auf einen gewissen Viruleuzgrad gebracht ist. Bei meinen Arbeiten wurde jede Pneumokokkencultur, die zu weiteren Versuchen bestimmt war, zunächst einer 6 bis 7 maligen unmittelbar auf einander folgenden Thierpassage unterzogen. Während der Dauer der Fortzüchtung wurde die Thierpassage regelmässig alle 4 Wochen und ausserdem immer nach je 14 Tagen die Uebertragung auf neue Nährböden vorgenommen. Auf diese Weise gelang es, die meisten der behandelten Stämme über ein Jahr lang lebend und rirulent zu erhalten. Sämmtliche untersuchten Stämme boten in ihrer 


\section{Morphologie}

das Bild des typischen Pneumococcus, wie es schon von Fränkel und Weichselbaum gezeichnet und seitdem durch zahlreiche Beobachtungen allgemein anerliannt ist. Es handelte sich also um paarweise gelagerte Mikroorganismen von der bekannten Lancettform (d. h. an je einem Ende spitz zulaufend und mit den breiten Seiten einander zugekehrt), mit deatlicher Kapselbildung im Thiercörper und positiver Färbbarkeit nach Gram. - Bei aller Uebereinstimmung in diesen Grundzügen wiesen indessen die einzelnen Stämme mannigfache und zum Theil ihrerseits wieder gewissen Gesetzen unterworfene Unterschiede auf. So war namentlich für die einzelnen Stämme eine bestimmte Grösse ihrer Individuen charakteristisch. Doch bestanden, wenn es sich um Abweichungen von der Norm handelte, diese, gleichviel welchem Material die Culturen entstammten, eher in einer ungewöhnlichen Grösse als in einer Kleinheit der Individuen, denn die letztere Eigenschaft war nur bei einem einzigen unserer Stämme vorhanden, bei diesem allerdings in so hohem Grade, dass seine mikroskopische Beobachtung zu einer äusserst schwierigen und ermüdenden Aufgabe wurde. Dabei bestanden zwischen der Herkunft der betreffenden Stïmme und ihrer Grösse gar keine Beziehungen, dagegen bestanden solche nach einer auderen Richtung hin, in welcher sich ebenfalls durchgreifende Unterschiede zwischen den untersuchten Stämmen zeigten; damit meine ich die einzelnen Pneumokokken innewohnende Eigenschaft der Kettenbildung, und zwar war der Zusammenhang zwischen dieser Eigenschaft und der Grösse der Individuen derart, dass es stets die grösseren Pneumokokhen waren, welche die längsten Ketten zu bilden pflegten. Dieses Vermögen kommt, wenn es einem Stamm überhaupt in besonderem Nausse eigen ist, sowohl in der Cultur wie im Thierkörper zum Ausdruck, wenn auch in letzterem nicht in so hohem Grade als bei der künstlichen Züchtung. Bei letzterer waren einzelne unserer Stämme (Stamm Nr. I Speichelcoccus, Stamm Nr. VII Tuberculosesputum-Pneumococcus, Stamm Nr. IX Panophthalmitis, Stamm Nr. XIII Meningitis) im Stande, Ketten von ausserordentlicher Länge zu bilden, die sich in mannigfachen Windungen durch das ganze Gesichtsfeld zogen, so dass der Gedanke nahe lag, es möglicher Weise mit Streptokokken zu thun zu haben; indessen ist der Pneumococcus von diesen Mikroorganismen, mit denen er durch die gemeinsame Eigenschaft der Kettenbildung nahe verwandt erscheint, bei hinreichend genauer Beobachtung wohl zu unterscheiden. Diese Unterscheidung lässt sich am besten dadurch treffen, dass man den betreffenden Organismus in den Thierkörper bringt. Dann zeigen sich nämlich im 
Herzblut, wo der Pneumococcus, wie seit jeher festgestellt ist, auch nach gleichzeitiger Einbringung zusammen mit anderen Mikroorganismen, z. B. aus dem Sputum, in Reincultur aufzutreten pflegt, neben einzelnen typischen Pneumokokken, ebenfalls die erwähnten, wenn auch hier bedeutend kürzeren und niemals gewundenen Ketten, die sich überdies durch Kapselbildung und Zusammensetzung aus einzelnen an einander gelagerten Diplokokkenpaaren als mit den Einzelformen zusammengehörig erweisen. Die Bildung der Ketten aus einzelnen Diplokokkenpaaren lässt sich überdies bei einiger Aufmerksamkeit selbst in den Culturen, wo die Kapseln mit den gewöhnlichen Mitteln nicht zu beobachten sind, erkemnen und zur Unterscheidung von den aus lauter gleichmässigen Kugeln gebildeten Ketten der Streptokokken rerwenden. - Diese Eigenschaft der Kettenbildung gehört zu den unveränderlichen Eigenschaften einzelner Stämme, denn wenn wir auch bei den meisten Pueumokokken im Condenswasser oder in Bouillonculturen kürzere Ketten auftreten sehen, so kommt es doch nur bei gewissen Stämmen zur Bildung der erwähnten langeu und gewundenen Ketten, und es fehlte andererseits einem unserer Stämme, und zwar dem schon eiumal angeführten kleinsten die Eigenschaft der Kettenbildung ganz. Ein Wechsel im Verhalten der Kettenbildung wurde bei keinem unserer Stämme beobachtet, dasselbe war rielmehr während der ganzen Dauer unserer Versuche im Thierkürper wie in der Cultur stets das gleiche.

Von den Beziehungen der Grösse und der Kettenbildung zur Virulenz der betreffenden Stämme soll in einem späteren Capitel die Rede sein. Ausser der bekannten Auordnung zu Diplokokken ist es besonders

$$
\text { Die Kapsel, }
$$

welche dem Pneumococcus das charakteristische Aussehen verleiht. Dieser Bestandtheil kommt jedoch erst bei färberischer Behandlung der Präparate recht zur Geltung, und zwar sind für diesen Zweck eine Reihe von Methoden angegeben worden. Darnach bedienen sich die Einen des Gentianaviolets, die Anderen einer Carbol-Fuchsin-Mischung, bei verschiedener Weise der Fixirung. Auf die erstere Art färben Albrecht und Ghon ${ }^{1}$, welche in Anlehnung an die Pittfield'sche Geisselfärbungsmethode folgende beiden Lösungen verwenden, die jedes Hal frisch vor dem Gebrauche zubereitet und filtrirt werden müssen:

1. Sol. alum. concentr. $1 \cdot 00$

" alkoh. concentr. Gentianariolet 10.00

2. Acid. tann. 1.00

Aqu. dest. $10 \cdot 00$

${ }^{1}$ Albrecht und Ghon, Beulenpest. II. S. 604. 
zu gleichen Theilen mischen, das Präparat damit, unter leichtem Erwärmen, auf dem Deckglas färben und, wenn nöthig, mit Alkohol oder verdünnter Essigsäure entfärben.

Des nämlichen Farbstoffes bedient sich auch $\mathrm{Pane}^{1}$, welcher dabei in nachstehender Weise verfährt.

Von einer frisch bereiteten alkoholischen 4 procentigen Gentianavioletlösung wird ein Tropfen zu $1 \mathrm{~cm}$ Wasser zugesetzt, damit einige Secunden gefärbt und mit Wasser abgespült. Falls zu stark gefärbt, mit Alkohol entfärben.

Besser als diese beiden Methoden gefiel uns unter denen, die Gentianaviolet anwenden, das Verfahren von Raebiger ${ }^{2}$, welcher sich zur Fixierung des Formalins bedient. Es geschieht dies in der Weise, dass 15 bis $20 \mathrm{grm}$ Gentianaviolet mit 100 bis $150 \mathrm{com}$ einer 4 procentigen Formalinlösung übergossen und nach Umrühren über Nacht stehen gelassen werden. Der Farbstoff darf dann nicht vollständig gelöst sein. Filtriren und damit ohne vorherige Fixirung oder Erwärmung des Deckglaspräparats 20 Secunden färben.

Wit Carbol-Fuchsin färben $\mathrm{Gabbi}^{3}$ nach raschem Trocknen über der Flamme eine Minute mit 1 bis 2 Tropfen folgender Mischung:

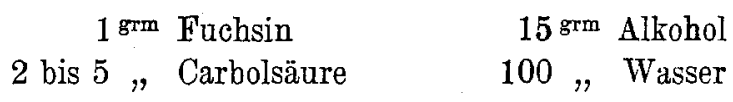

und Boni ${ }^{4}$, dessen Verfahren sich dadurch ausgezeichnet, dass er zum Zweck der Fixirung den Gewebssaft, in dem die Bakterien sonst suspendirt sind, durch eine Eiweisslösung zu ersetzen sucht. Das Weisse eines Hühnereies wird mit $50 \mathrm{grm}$ Glycerin und 2 Tropfen Formalin geschüttelt und filtrirt. Diese Lösung ist, wie wir uns überzeugt haben, mehrere Monate haltbar. Das Präparat wird mit einem Tropfen dieser Mischung auf dem Deckglase verrieben und unter leichtem Erwärmen, bis zu dem Grade, dass eben weisse Dämpfe aufsteigen, vorsichtig über der Flamme getrocknet und dann ganz kurz mit Carbol-Fuchsin gefärbt. Mit diesem Verfahren meint $B 0$ ni die Kapsel auch nachweisen zu können, wo unsere anderen Methoden nicht ausreichen. Er will nämlich sowohl in älteren Pneumokokkenculturen, als auch in Culturen anderer, bisher für kapsellos gehaltener Bakterien solche Bildungen nachgewiesen haben. - Dass man nach der genannten Methode sehr schöne Bilder von Kapseln erhält und

${ }^{1}$ Pane, Riforma med. Nr. 98. - Ref. Centralbl. f. Bakteriologie. Bd. XXIV. S. 289.

${ }^{2}$ Raebiger, Zeitschrift für Fleisch- und Milchhygiene. Bd. XI. S. 68.

${ }^{3}$ Gabbi, La Riforma med. 1889. Nr. 31.

4 Boni, Ref. Centralblatt für Bakteriologie. Bd. XXVIII. p. 705. 
auch in älteren Culturen Erscheinungen sieht, die für Kapseln gehalten werden können, sei zugegeben; doch haben wir uns des Eindrucks nicht erwehren können, als ob gerade dieses Verfahren am leichtesten zur Entstehung von Kunstproducten Veranlassung geben könnte. Wir kounten auch, was die Schönheit des Prïparats anlangt, keiner dieser Methoden vor der einfachen Anwendung von verdünntem Carbol-Fuchsin (1:4 oder 1:5) oder dem Gram'schen Verfahren den Vorzug geben. Mittels dieser beiden Methoden lassen sich die Kapseln in Gewebssäften von Thieren, Sputum und in frisch aus dem Thierkörper angelegten Culturen - bis zur 3. bis 4. Generation, am besten bei Verwendung von Blutagar - sehr schön zur Darstellung bringen. Ebenso wenig wie besonderer Färbungsmethoden bedarf es unseres Erachtens besonderer Nährmedien, wie sie gleichfalls zur besseren Sichtbarmachung der Kapsel angegeben worden sind.

Wie bei allen Bakterienarten treten auch beim Pneumococcus in alten Krankheitsherden die sogenannten

\section{Involutionsformen}

auf. Solche beschreiben u. A. auch Stoltz ${ }^{1}$ und Michaelis ${ }^{2}$, welch' letzterer sie in 28 Fällen von seröser Pleuritis angetroffen hat. Vou dem Vorkommen solcher Involutionsformen konnte ich mich ebenfalls überzeugen, wenn ich Material aus alten Eiterherden zur Untersuchung bekam. Die darin vorgefundenen Pneumokokken machten dann den Eindruck, als ob die Componenten der einzelnen Paare immer mehr aus einander wichen und dabei gleichzeitig immer kleiner würden, bis das Ganze schliesslich wie ein Bacillenleib aussah, von dem im ungefärbten Präparat die Enden stärker lichtbrechend, bezw. im gefürbten nur diese mit dem Farbstoff tingirt erschienen. Mit diesem Vorgang geht zugleich ein Verlust der Kapsel Hand in Hand. Ganz ähnliche Gebilde sah ich bei einem meiner Pneumokokkenstämme, den ich über 1 Jahr lang zu Versuchen gezüchtet hatte, vorübergehend auch in den Culturen auftreten. Dabei war aber die Virulenz des betreffenden Stammes noch erhalten und durch geeignete Erhöhung derselben mittelst besonderer, später näher zu schildernder Thierpassagen gelang es, die Involutionsformen aus der Cultur verschwinden zu lassen. Hingegen wurde in alten, sich selbst überlassenen Culturen, deren Virulenz verloren gegangen war, zwar eine Aenderung der Conturen und granulöser Zerfall der Individuen, aber niemals das Vorkommen bacillenähnlicher Formen beobachtet.

${ }^{1}$ Stoltz, Centralblatt für. Bakteriologie. Abth. I. Bd. IV. S. 337.

2Michaelis, Berliner klin. Wochensehrift. 1902. Nr. 20. 
Das Verhalten der Pneumokokken in der

\section{Cultur}

ist bekannt, und hierin zeigten die von uns untersuchten Stämme im Allgemeinen grosse Uebereinstimmung. Bei allen fand sich die allbekannte Wahrnehmung bestätigt, dass sie bei einer schwach alkalis chen Reaction des Nährmediums am besten gedeihen, obwohl sie sich auch noch eine schwach saure oder stark alkalische Reaction gefallen lassen. Auch fand ich bestätigt, dass der Pneumococcus zwar die Gegenwart ron Sauerstoff rorzieht, aber auch anärob fortkommen kann, denn bei Anlegung von. Stichculturen in Agar oder Gelatine siebt man auch Wachsthum in Form einzelner Colonieen längst des Stichcanals auf treten. - Als Regel stellte es sich heraus, dass diejenigen Stämme, welche in der Cultur am üppigsten wuchsen, die geringste Virulenz besassen und umgekehrt, eine auch bei anderen Bakterien beobachtete Erscheinung. In. flüssigen Medien, insbesondere dem gebräuchlichsten derselben, der Bouillon, kamen die Unterschiede der Wachsthumsenergie in dem Grade der durch die Bakterien verursachten wolkigen Trübung zum Ausdruck. Auf festen Nährböden stellten sich die Unterschiede so dar, dass die weniger virulenten Stämme compact zusammenhängende grauweisse Beläge bildeten, während die virulenteren in Form durchscheinender Ueberzüge wuchsen. Die Farbe derselben war entweder ein zartes Perlgrau oder sie waren ganz wasserklar wie Thautropfen, mit denen man sie öfters verglichen hat. Letztere Wachsthumsform zeigte sich aber immer nur vorübergehend kurz nach der Isolirung und ging nach 2 bis 3 Generationen in die erwähnte perlgraue Form über, die manchmal auch einen grünlich metallischen Schimmer zeigte. Diese Unterschiede der Erscheinungsformen traten am deutlichsten bei Verwendung von Agarnährböden hervor. Bei Wachsthum anf erstarrtem Serum trug die Eigenfarbe dieses Nährbodens dazu bei, die Unterschiede zu verwischen und auf Gelatine wuchsen die Pneumokokken im Allgemeinen spärlich, das heisst in Form von äusserst kleinen, leicht gelblichen, weit aus einander liegenden Colonieen. Dieses spärliche Wachsthum auf Gelatine rührt jedenfalls davon her, dass der Pneumococcus als ein pathogener Mikroorganismus an eine höhere Temperatur angepasst ist. Zwei von meinen Stämmen konnten überhaupt auf Gelatine auch bei einer Temperatur von 27 bis $28^{\circ} \mathrm{C}$. nicht zum Wachsthum gebracht werden. Die übrigen wuchsen auch bei dieser relativ hohen Temperatur nur in der gekennzeichneten spärlichen Weise, und bei noch niedrigeren Temperaturen (Zimmertemperatur $18^{\circ} \mathrm{C}$.) waren bloss noch Spuren von Wachsthum bemerkbar. Eine Mittelstellung nahmen drei 
Stämme ein, welche bei Zimmertemperatur gar nicht mehr wuchsen, bei 27 bis $28^{\circ}$ dies zwar noch thaten, aber nach bedeutend längerer Zeit als die anderen, nämlich in 2 bis 3 Tagen. Eine Ausnabme bildete nur der ron $\mathrm{mir}$ in einer besonderen Abbandlung ${ }^{1}$ beschriebene Pneumococcus, welcher schon nach seinem Vermögen, Gela tine zu verflüssigen, eine Sonderstellung einnahm und der auch noch bei Temperaturen ron $9^{\circ} \mathrm{C}$. im Eisschrank üppiges Wachsthum zeigte. Eine Beziehung dieser Wachsthumsverschiedenheit zur Herkunft oder zur Virulenz der Stämme konnte nicht nachgewiesen werden. Ebenso wenig konnte eine solche Beziehung zu der durch manche Stämme verursachten Gerinnung der Milch, welche für alle ein gutes Nührmedium darbot, gefunden werden. Den Pneumococcus auf Kartoffeln zu züchten, ist uns nicht geglückt.

Aus diesen Erörterungen geht zur Genüge hervor, dass beim praktischen Arbeiten mit Pneumokokken am besten Bouillon- oder Agarü̈hrbüden von schwach alkalischer Reaction Verwendung finden, und dass auch gegen erstarrtes Serum nichts einzuwenden ist. Auf durchsichtigen festen Nährböden - Agar oder Gelatine - sehen die Pneumokokkencolonieen bei schwacher Vergrösserung körnig ans, sind von kreisrunder Form und bieten ausser einem dunkleren Centrum und einer etwas helleren Randzone keine Besonderheiten.

Im Finzelnen wurden verschiedene, theils von anderen Autoren angegebene Nährbüden geprüft, theils neue Zusammensetzungen versucht. Nachgeprüft wurde z. B. die von Guarnieri ${ }^{2}$ angegebene Agargelatine mit hohem Peptongehalt. Dieser Nährboden, den man auch der Bruttemperatur aussetzen kanu, bewährte sich in unseren Versuchen insofern, als er den Pneumokokken sehr günstige Wachsthumsbedingungen darbot, und die Einzelcolonieen darin eine aussergewöhnliche Grösse erreichten. Bemerkenswerth ist auch, dass auf diesen Nährböden alle Stämme, die überhaupt Neigung zur Kettenbildung zeigten, ganz besonders lange and verschlungene Ketten bildeten.

Diesen Vorzügen stehen andererseits einige erhebliche Nachtheile gegenüber, die das Arbeiten mit dem erwähntem Nährmedium zu einem unangenehmen machen: kann man sich desselben doch nicht wie des Agars zur Anlegung von Strichculturen bedienen, da es bei Brüttemperatur zu einer halbflüssigen Masse zusammensickert. Doch kann man dem Uebelstand durch Anlegung von Stichculturen, in denen der Pneumococcus,

${ }^{1}$ Centralblatt fiur Batteriologie. Bd XXXII. S. 573.

'Guarnieri, Atti dell' Accad. med. di Roma. 1888. Vol. IV. Vgl. Flügge, Die Mikroorganismen. Bd. II. S. 118. 
wie bereits erwähnt, längs der Impfstiche wucherte, noch abhelfen. Der grösste Nachtheil dieses Nährbodens ist aber der, dass man die Abimpfung niemals vornehmen kann, ohne dabei grosse Theile des Substrates mit auf die anzufertigenden Präparate, oder die einem Versuchsthiere einzuspritzende Aufschwemmung hinein zu bekommen.

Ebenso wenig erwies sich die von Carnot und Fournier ${ }^{1}$ empfohlene Benutzung von Hirnsubstanz zur Bereitung von Agar in unseren Versuchen von Nutzen. Allerdings hatten diese Autoren mit Kaninchen- und Menschengehirn gearbeitet, während wir das leichter erhaltbare Kalbsgehirn benutzten, in dem Glauben, dass dies für den gewünschten Zweck keinen Unterschied machen könne.

Ein solcher mit Gehirnsubstrat hergestellter Agar filtrirt sehr schwer und büsst bei der Filtration seinen Nährwerth in so hohem Maasse ein, dass nur noch spärliches Wachsthum darauf eintritt. Verzichtet man andererseits auf die Klärung des Agars durch Filtration, so wird derselbe gerade bei dieser Art der Herstellung besonders trübe und dadurch unangenehm.

Eines von dem üblichen völlig abweichenden Verfahrens zur Herstellung eines für den Pneumococcus geeigneten Nährbodens bedienten sich Adolph Smith ${ }^{2}$ und Grawitz und Steffen ${ }^{3}$, indem sie pneumonisches Sputum durch einstündiges Erhitzen auf $65^{\circ}$ C. zur Erstarrung brachten, dasselbe dann fractionirt sterilisirten und darauf Culturen anlegten. Doch machten schon die Erfinder dieser Methode darauf aufmerksam, dass sebr mucinreiche Sputa bei Erhitzung leicht flüssig, statt hart werden. Uns ist es überhaupt niemals geglückt, eine Verllüssigung trotz sorgfältigster Behandlung der Sputa zu vermeiden. Wir versuchten dinn, veranlasst durch das üppige Wachsthum der Pneumokokken auf dem Guarnieri'schen Nährboden, ob dies nicht vielleicht nur dessen hohem Peptongehalt zu verdanken sei unḋ stellten, um den Nachtheil des halbflïssigen Nährsubstrats zu vermeiden, einen Agar von erhöhtem Peptongehalt her. Auf diesem konnten wir denn auch ein reichlicheres Wachsthum beobachten und ganz besonders dann, wenn dieses Medium noch mit Blut (Kaninchenoder Menschenblut) bestrichen wurde. Ein solcher Blutzusatz erwies sich übrigens auch bei allen anderen Nährböden von Vortheil, namentlich zeigten sich dann die Kapseln besonders schön ausgebildet. Für gewöhnliche Zwecke genügt es indessen vollständig, wenn man sich des

${ }^{1}$ Carnot et Fournier, Arch. de méd. expér. el d'anat. pathol. T. XII. p. 357.

- Ref. Baumgarten's Jahresbericht. 1900. Bd. XVI. S. 37.

${ }^{2}$ Adolph Smith, Centralblatt für klin. Medicin. 1893. S. 625.

${ }^{3}$ Grawitz u. Steffen, Centralblatt für Bakteriologie. 1894. Bd. XVI. S. 257. 
zur Züchtung des Pneumococcus altbewährten Glycerinagars, und zwar von der erwähnten schwach alkal ischen Reaction bedient, da ein solcher einfach herzustellen ist und die erwähnten complicirteren Medien nur in der Ueppigkeit der darauf gewachsenen Culturen, aber nicht in deren Haltbarkeit und Virulenz sich überlegen zeigten. Zur Erhaltung der Virulenz, für die man schon alle möglichen Auskunftsmittel angenommen hat, fanden wir ein sehr einfaches Verfabren als besonders geeignet; wir benutzten nämlich die Coagula von steril in einem Erlenmey er' schen Kölbchen aufgefangenem normalem Kaninchenblut, dessen abgesetztes Serum anderem Zwecke diente, zur Anlegung von Pneumokokkenculturen und fanden, dass sich alle darauf gezüchteten Stämme ohne weitere Umzüchtung $4 \frac{1}{2}$ Monate lang lebensfähig und vollvirulent erhielten. Der gewachsene Pilzrasen ist allerdings auf diesem Substrat, dessen rothbraune, in's Grünliche schimmernde Farbe er annimmt, sehr schwer erkennbar.

Ueber das Wachsthum der Pneumokokken in flüssigem Normalserum soll in einem besonderen Capitel, wo von den Beziehungen der Pneumokokken zum Serum überhaupt die Rede sein wird, Näheres mitgetheilt werden.

\section{Ueber die Virulenz}

der Pneumokokken weiss man schon lange, dass sie grossen Schwankungen unterliegt. Im Besonderen ist der Unterschied in der Virulenz zwischen Speichel-und Pneumonie-Pneumokokken schon Fränkel aufgefallen, und es bedurfte, wie Eingangs bereits erwähnt, erst eines intensiveren Studiums, bevor man darüber zur Klarheit kam, dass der die Schleimhäute gesunder Individuen bewohnende Mikroorganismus und der Erreger der Pneumonie ein und derselben Bakterienart angehörten. Späterhin lernte man dann den Pneumococcus als einen viel weiter verbreiteten Krankheitserreger beim Menschen kennen: man hat diese Bakterien in Entzündungsprocessen verschiedener Art, so bei Pleuritis, Pericarditis, Meningitis, Gehirnabscessen, Arthritis und Otitis media, aber auch als Erreger septicämischer Infectionen gefunden. Hat man doch sogar in Fällen von croupöser Pneumonie die specifischen Mikroorganismen öfter aus dem Blut der betreffenden Kranken gezüchtet.

Wir hatten uns nun zur Aufgabe gemacht, eine Reihe verschiedener Pneumokokken zu untersuchen, namentlich in der Absicht, uns darüber Klarheit zu verschaffen, ob, wie Manche wissen wollen, es verschiedene Arten von Pneumokokken gäbe, oder in welcher Beziehung die aus verschied en en Qu ellen stammenden Pneumokokken sonst zu einander ständen. 
Pneumokokken aus menschlicher Septicämie standen uns nicht zu Gebote, dagegen hatten wir eine Anzahl aus typischen Pneumoniefällen isolirt, ferner solche aus tuberculösem Sputum, aus Meningitis, Gehirnabscessen, Otitis media, Panophthalmitis, sowie die leicht zu erhaltenden Speichelkokken gesunder Personen. Nach dieser Eintheilung liesse sich zwar im Allgemeinen der Satz aufstellen, dass die Virulenz der Pneumokokken nach ihrem Ursprung eine verschiedene ist, indem die Pneumoniekokken die höchste, die aus Sputum (tuberculösem und normalem) und aus frischen entzündlichen Processen eine mittlere, und die aus alten Eiterherden (Empyem, Gehirnabscessen) gar keine Virulenz besitzen. Im Einzelnen kommen jedoch von dieser Regel vielfache Ausnahmen vor; so fanden wir auch PneumoniePneumokokken ohne Virulenz, ebenso einen avirulenten Stamm von Meningitis, ferner konnten wir aus 2 Fällen von Otitis media je einen hochvirulenten und einen arirulenten Stamm isoliren, wogegen die Speichelkokken mehr eine konstante Virulenz mittleren Grades besassen. Hierzu sei noch bemerkt, dass die Pneumokokken aus tuberculösem Sputum besonders leicht dem Absterben bei der künstlichen Züchtigung ausgesetzt schienen, so dass es überhaupt immer nur gelang, einen von etwa 4 bis 5 solchen Stämmen dauernd zur weiteren Untersuchung am Leben zu erhalten. - Die Virulenz der Pneumokokken richtet sich natürlich auch nach der Art der inficirten Versuchsthiere und dem Vorgang der Infection. Wir wissen seit den Untersuchungen Gamaleĩa's ${ }^{1}$, dass am empfänglichsten Mäuse und Kaninchen, weniger empfünglich Meerschweinchen, Schafe und Hunde sind, während Geflügel bisher für unempfänglich galt. Letzteres konnten wir jedoch nicht bestätigen, denn es gelang uns wiederholt, mit einem unserer virulentesten Stämme eine tödtliche Infection bei Tauben herrorzurufen. Doch sind diese Beziehungen zwischen Virulenz und Versuchsthier mitunter ganz specifisch, da es Pneumokokkenstämme giebt, die nur für Mäuse virulent, für Kaninchen dagegen avirulent sind und umgekehrt. Der Infectionsmodus spielt insofern eine Rolle, als, wie bei den meisten Bakterien die intravenöse Einverleibung am wirksamsten und die intraperitoneale wieder der subcutanen überlegen ist. Bei den meisten der von uns untersuchten Stämme wurde die genaue Feststellung des Virulenzgrades gegenüber Mäusen als dem am leichtesten in grösseren Mengen zu bearbeitenden Versuchsthier unternommen, wobei ausschliesslich die in traperitoneale Infection angewandt wurde. Bei diesen Versuchen zur Virulenzbestimmung wurden durchgängig 24 Stunden alte Bouillonculturen aus dem Herzblut der

${ }^{1}$ Gamaleïa, Annales de l'Institut Pasteur. T. II. p. 440. 
zuletzt getödteten Thiere benutzt; in den Fällen, wo Bouillonculturen sich von vornherein als wirkungslos erwiesen, bedienten wir uns der Aufschwemmungen von Agarculturen, um so noch grössere Bakterienmengen ohne allzu grosse Erhöhung der zur Suspension nöthigen Flüssigkeitsmenge einverleiben zu können. Doch sei bemerkt, dass auch eine derartige Steigerung der einverleibten Bakterienmenge bei Stämmen, deren Bouillonculturen der Virulenz ermangelten, keine Wirkung hatte. Wir konnten solche Stämme daher mit gutem Recht als avirulent bezeichnen. Dies waren unter 24 Stämmen im Ganzen 1 Stamm aus Pneumonie, 1 a s Otitis media, 2 aus Empyem, 2 aus Meningitis und 1 aus Gehirnabscess. Führte hingegen die Einspritzung einer jungen Bouilloncultur zum Tode des Versuchsthieres, so wurden unter fortwährender Verringerung der Dosis weitere Thierpassagen rorgenommen, bis eine Grenze erreicht war, bei der die Versuchsthiere nicht mehr starben. Traf dies ein, so wurde noch eine Reihe von Thieren mit der zuletzt tödtlichen Dosis geimpft und dann nach Anlegung neuer Bouillonculturen aus diesen Thieren die Dosis weiterhin versuchsweise herabgesetzt, um zu sehen, ob die Virulenz der betreffenden Pneumokokken durch die letzte Thierpassage nicht eine weitere Steigerung erhalten hätte. Es gelang uns nämlich dadurch, bei einer Reihe von Stämmen die Virulenz gegenüber Mäusen erheblich zu steigern und das Verfahren wurde in der erwähnten Weise fortgesetzt, bis von den Versuchsthieren keines mehr der Impfung erlag. Die bei der vorangegangenen Infection noch tödtliche Dosis wurde dann als Dosis letalis minim a bezeichnet. Um mit einer constanteren Maasseinheit zu arbeiten, bedienten wir uns auch bei Bouillonculturen der Maassöse und schwemmten das damit entnommene Material in $1 \mathrm{~cm}$ steriler Bouillon auf. Bei der geringsten tödtlichen Dosis angelangt, wurde die Zahl der in der Maassöse enthaltenen Bakterien durch die Anlegung von Agarplatten und Zäblung der aufgegangenen Colonieen festgesetzt. Diese nach zahlreichen Thierpassagen in der geschilderten Weise erreichte und durch weitere Passagen nicht mehr za steigernde, zur Tödtung einer Maus erforderliche Menge betrug bei den Speichelkokken, deren Virulenz eine, wie schon gesagt, ziemlich constante war, gerade eine solche Maassöse, hingegen schwankte die tödtliche Dosis bei den Pneumonie-Pneumokokken zwischen 1/2000000 (entsprechend 5 Colonieen) und 1/10000 (entsprechend 200 Colonieen derselben Oese). Nur bei dem in jeder Beziehung eine A usnahme bildenden, bereits erwähnten, Gelatine verflüssigenden Pneumococcus war die Virulenz zwar rorhanden, aber doch erheblich geringer. Die kleinste tödtliche Gabe betrug nämlich $1 / 2 \mathrm{em}$ Bouilloncultur.

Bei den aus entzündlichen Processen stammenden Pneumokokken, 
die, wie ebenfalls schon bei der allgemeinen Besprechung erwähnt, eine mittlere Stellung zwischen den genannten einnahmen, schwankte die tödtliche Menge, soweit sie nicht überhaupt avirulent waren, zwischen einer ganzen und $1 / 50$ Oese.

Die bei den Pneumonie-Pneumokokken von uns gefundene noch tödtliche Gabe ron $1 / 2000000$ Oese dürfte wohl der höchsten, bisher überhaupt festgestellten Virulenz dieses Mikroorganismus entsprechen, denn sie findet in der Litteratur nur in den Angaben Eyre und Washbourn's ${ }^{1}$ ein Gegenstück, indem diesen Autoren zu Folge 1/1000000 Oese eines Pneumococcus auf Kaninchen noch tödtlich wirkte. Es handelte sich dabei ebenfalls um einen Pneumonie-Pneumococcus. Ueber die Vergleichung mit Pneumokokken aus anderen Quellen liegen keine Angaben vor.

Selbstrerständlich spielt für die Beurtheilung der Virulenz auch die Zeit, innerhalb deren die Versuchsthiere der Infection erliegen, eine Rolle. In unseren Versuchen starben die Mäuse, wenn sie mit hochvirulenten Stämmen geimpft waren, selbst nach den kleinsten Gaben stets innerhalb 12 bis 16 Stunden, bei Stämmen von mittlerer Virulenz bedurfte es 24 Stunden und nur in Ausnahmefällen vergingen 2 bis 3 mal 24 Stundeu bis zum Untergange der Versuchsthiere an Pneumokokkeninfection; der erwähnte hochvirulente Stamm von Eyre und Washbourn tödtete in der angegebenen kleinsten Menge die Mäuse innerhalb 4 Tagen.

Da bei den aus menschlicher Pneumonie gewonnenen Pneumokokken von mehreren Autoren Unterschiede in der Virulenz während der einzelnen Stadien dieser Krankheit angegeben worden sind, so versuchten wir, auch dieser Frage näherzutreten. Indessen stellte sich nun dabei eine Schwierigkeit entgegen, deren Ueberwindung uns nicht gelungen ist. Wenn wir nämlich, um die Virulenz der Pneumokokken bei der Entnahme derselben unmittelbar aus dem Sputum ohne jegliche Erhöhung durch Thierpassagen zu bestimmen, die Isolirung des Bacteriums direct aus dem Auswurf rersuchten, so hatte, beror uns dies, mittels Ausstrich-oder Plattencultur, gelang, die Virulenz des Bacteriums bereits derartig abgenom men, dass, wenn die Reincultur erhalten war, die Versuchsthiere daran nicht mehr zu Grunde gingen, was wohl bei den Thieren der Fall war, die mit demselben Sputum geimpft waren, aus dem die Reincultur stammte. Da wir dieses Verfahren in $17 \mathrm{Fällen}$ mit dem gleichen negativen Resultate versuchten, mussten wir auf eine derartige Vergleichung der Virulenz in den verschiedenen Stadien der Pneumonie verzichten. - Da nun in der Bakteriologie kein einziges Beispiel dafür bekannt ist, dass ein virulenter Organismus diese Eigenschaft bei einer künstlichen Züchtung

${ }^{1}$ Eyre and Washbourn, Journ. of Path. and Bact. Vol. V. p. 13. 
von nur 3 bis 5 tägiger Dauer verliert und der Pneumococcus sonst, wenn er auch nur einmal durch den Thierkörper gegangen ist, seine Virulenz viel länger in den Culturen zu bewahren pflegt, so müssen wir auf Grund unserer Versuche annehmen, dass der Pneumococcus im menschlichen Sputum eine hohe Virulenz von vornherein nicht besitzt und er erst beim Durchgang durch den Thierkörper aus dem Auswurf zu einem Organismus von den bekannten pathogenen Eigenschaften wird.

In diesen Ausführungen haben wir bereits die Frage der Erhaltung der Virulenz des Pneumococcus gestreift. Auch diese Frage haben wir zum Gegenstand eingehender Untersuchungen gemacht, deren Ergebnisse wir im Folgenden mittheilen. Fs ist bekannt, dass der Pneumococcus ein Mikroorganismus ist, dessen Virulenz in der Cultur sehr rasch abnimmt. Doch liegen in der Litteratur einige Angaben von Autoren vor, denen es geglückt ist, Pneumokokken längere Zeit ohne Vornahme von Thierpassagen: ja sogar ohne Uebertragung auf neue Nährmedien virulent zu erhalten. So gelang es Fo à 60 Tage lang, indem er das Blut pneumokokkeninficirter Thiere nach 24 stündigem Aufenthalt bei Brüttemperatur im Dunkeln und in der Kälte aufbewahrte. Zu ungefähr demselben Resultate (67 Tage) will Sclavo² durch Aufheben der Milz inficirter Thiere in Glycerin gekommen sein, und die Erhaltung der Virulenz für etwas hürzere Dauer (50 Tage) erreichte er durch Anlegen von Culturen in frischen Hühnereiern. Andere Autoren haben ähnliche Resultate mit noch anderen Methoden erlangt. Wir haben ron deren Nachprüfung abgesehen und vielmehr darauf Werth gelegt, die Haltbarkeit der Culturen auf den üblichen Medien zu bestimmen, und sind in der Lage, darüber folgende Angaben machen zu können.

Am geringsten ist die Haltbarkeit ron Bouillonculturen; dieselben sterben nach 2 bis 3 Wochen völlig ab. Agarculturen halten. sich länger, nämlich 1 bis $1 \frac{1}{2}$ Monat, und Culturen auf Glycerinagar sogar 2 bis $2 \frac{1}{2}$ Monate und ungefähr ebenso lange Culturen auf Blutagar oder erstartem Serum.

Diese Resultate entsprechen also ungefähr denen der italienischen. Forscher, oder übertreffen diese sogar. Jedenfalls geht aus unseren Versuchen zur Genüge hervor, dass es zur Erhaltung der Virulenz und der Lebensfähigkeit des Pneumococcus für die angegebene Zeit besonderer Methoden nicht bedarf, die üblichen Nährböden vielmebr genügen. Richtig ist allerdings, dass Blut ganz besonders für die Erhaltung des

${ }^{1}$ Foà, Diese Zeitschrift. 1893. Bd. XV. S. 369.

'Sclavo, Annales de l'Institut Pasteur. 1893. T. VII. p. 221. 
Pneumococcus und seiner Virulenz günstig ist. Es gelang uns nämlich, wie schon erwähnt, auf den Coagulis von steril entnommenem, normalen Kaninchenblut, dessen Serum anderen Zwecken gedient hatte, eine grössere Anzahl unserer Pneumokokkenstämme über 4 Monate vollvirulent zu erhalten. Es ist dies eine relativ sehr lange Zeit für die Aufbewahrung von Pneumo. kokken ohne Umzüchtung, wenngleich sich in der Litteratur 2 Angaben finden, denen $z u$ Folge die Erhaltung der Pneumokokken ohne. Umzüchtung über ein Jahr lang geglüclst ist. Die eine dieser Angaben stammt ron G. Bernabeo', die andere von Bezançon und Griffon ${ }^{2}$, die ebenfalls Blut, aber im defibrinirten Zustande und in Verdünnung mit Ascitesserum anwandten.

Unsere obigen Angaben sind noch dahin zu ergänzen, dass natürlich die Lebensfähigkeit der Culturen bei den einzelnen Stämmen verschieden ist, und zwar lässt sich die allgemeine Regel aufstellen, dass je virulenter ein Pneumokokkenstamm ist, desto besser und länger sich auch seine Cultur hält; was auch Weichselbaum mit Recht in seinem Referat über die Pneumokokken im Handbuch von Kolle-Wassermann hervorhebt. Dem Absterben der Culturen pflegt ein Verlust der Virulenz voranzugehen, nach welchem immer noch eine Weiterzüchtung von 3 bis 5 Generationen müglich ist.

Nach diesen Angaben über die Virulenz der Pneumokokken und ibre Erhaltung müssen wir bei der Besprechung der

\section{Patbologischen Veränderungen}

verweilen, welche der genannte Mikroorganismus im Körper geeigneter Versuchsthiere hervorruft.

Alle bisherigen Untersucher stimmen darin überein, dass die am meisten empfänglichen Thiere - Kaninchen und Mäuse - gleichviel in welcher Weise inficirt, an einer allgemeinen Septicämie zu Grunde gehen und man bei der Section den Krankheitserreger im Herzblute und in der Milz am reichlichsten findet. In Bezug auf Einzelheiten des Sectionsbefundes lauten indessen die Angaben der Autoren rerschieden, namentlich über die Beschaffenheit der Milz; welche bald als weich und hyperämisch, bald als fibrös und hart beschrieben wird. Fo $\grave{a}^{3}$ unterscheidet darnach sogar verschiedene Rassen des Pneumococcus, während Banti ${ }^{4}$ der Züchtungsweise des Pneumococcus, ob aërob oder anaërob, die Verschiedenheit der pathogenen Wirkung zuschreibt.

${ }^{1}$ Bernabeo, Riforma medica. Vol. XII. Nr. 21.

'Bezançon et Griffon, Annales de l'Institut Pasteur. T. XIV. p. 449.

${ }^{3}$ Foà, Diese Zeitschrift. 1893. Bd. XV. S. 369.

- Banti, Arch. di anat. norm. e pathol. 1890. Vol. V. p. 62. 
Im Gegensatz zu diesen Autoren habe ich in meinen zahlreichen Versuchen niemals eine harte und fibröse Beschaffenheit der Milz, sondern immer nur ein weiches, blutreiches, wenig vergrössertes Organ g efunden. Im Uebrigen bot die Bauchhöhle nach intraperitonealer Infection das Bild einer ausgedehnten Peritonitis von sero-sanguinolentem (bei Mischinfection mittelst Sputums auch wohl eitrig-sanguinolentem) Charakter. Von den Bauchorganen zeichnen sich ausser der Milz noch die Nieren durch Hyperämie aus. Der Tod der Thiere erfolgte bei jeder Art der Infection unter dem Bilde einer Septicämie mit besonders reichlichem Pneumokokkenbefunde im Herzblut und in der Milz. Bei Kaninchen, weniger bei Mäusen, fand ich auch nach intraperitonealer Impfung mehrmals eine seröse Pericarditis. Bei Impfung in die Lunge von Thieren haben andere Autoren, z. B. Banti ${ }^{2}$ umschriebene Pneumonieen und Pleuritiden beobachtet, was ich sowohl bei Kaninchen wie bei Mäusen bestätigt fand; auch in diesem Falle erlagen aber die Thiere einer Septicämie. Abscessbildung, wie sie gleichfalls von mehreren Autoren nach subcutaner Impfung als Wirkung zur Allgemeininfection nicht genügender Gaben beschrieben worden ist, habe ich in meinen Versuchen niemals angetroffen, die Thiere starben, wie gesagt, entweder an Septicämie oder sie überlebten die Impfung olne weitere Krankheitserscheinungen; höchstens zeigte sich nach subcutaner Impfung ein leichtes Infiltrat an der Impfstelle. Eine besondere und nur in einem Falle von mir bei ungenügender Gabe beobachtete Erscheinung war ein ausgedehntes Erysipel der Bauchhaut, welches ausheilte. Hingegen ist es mir nicht gelungen, künstlich ein ausgesprochenes Erysipel durch Pneumokokien zu erzeugen, wie dies Neufeld ${ }^{2}$, Schürmeyer ${ }^{3}$ und Anderen geglückt ist; einige Male traten allerdings am Kaninchenohr, wo die Oberfläche nach leichter Scarification inficirt wurde, Veränderungen auf, die man allenfalls als erysipelartig ansprechen konnte.

\section{Verhalten der Pneumokokken zum Serum.}

Haben wir in den bisherigen Capiteln gewissermaassen die classischen Eigenschaften unseres Bacteriums besprochen, d. h. diejenigen, welche man von jeher zum Gegenstande der Untersuchung zu machen pflegte, und dabei - wie dies aber bei unserer Aufgabe einer möglichst vollständigen Bearbeitung des Pneumococcus nicht zu rermeiden war -

${ }^{1}$ Banti, Archiv. per le scienze med. Vol. XIII. Nr. 3.

${ }^{2}$ Neufeld, Diese Zeitschrift. Bd. XXXVI. S. 254.

Schürmeyer, Centralblatt für Bakteriologie. Bd. XXV. Nr. 5 u. 6. S. 183. 
manches schon Bekannte wiederholen müssen, so haben wir doch andererseits auch den Anforderungen der modernen Wissenschaft Rechnung getragen, welche den Beziehungen zwischen Bakterien und Immunserum nachzugehen und die dabei gewonnenen Ergebnisse zu diagnostischen und therapeutischen Zwecken nutzbar zu machen sucht. An hierauf gerichteten Bestrebungen hat es zwar auch bei dem Studium des Pneumococcus bisher schon nicht völlig gefehlt. Indessen ist die Zahl derer, die sich damit beschäftigt haben, klein und die Summe der von ihnen mitgetheilten Erfahrungen noch nicht bedeutend. Es rührt dies unseres Erachtens daher, dass die meisten der betreffenden Forscher sich vielfach mit den Beziehungen des Pneumococcus zu menschlichem Serum als dem praktisch wichtigsten beschäftigt haben, ohne dass vorher genügende Erfahrungen an dem leichter und umfassender $\mathrm{zu}$ bearbeitenden Material der Laboratoriumsthiere vorlagen. Wir hielten es daher für rathsam, hier einzusetzen und zunächst das Verhalten der Pneumokokken gegenüber dem Serum geeigneter Versuchsthiere, und zwar zunächst gegenüber normalem und dann auch gegen Immunserum zu prüfen.

Auf das verschiedene Verhalten des Pneumococcus gegenüber normalem und Immunserum hat bereits Metschnikoff ${ }^{1}$ hingewiesen, indem er darauf aufmerksam machte, dass der Pneumococcus in Immunserum in Form länger verschlungener Ketten, in normalem Serum hingegen stets in Gestalt von einzelnen Individuen oder höchstens kürzeren Ketten zum Wachsthum gelangte, eine Erfahrung, welche später von Bezançon und Griffon ${ }^{2}$, sowie von $\mathrm{Pane}^{3}$, Huber ${ }^{4}$ und Neufeld ${ }^{5}$ bestätigt wurde. Diese Verschiedenheit zwischen den beiden Serumarten kommt im Verhalten des Pneumococcus, den letztgenannten Autoren zufolge, auch schon makroskopisch zum Ausdruck, indem sich in normalem Serum eine gleichmässige 'Trübung wie in Nährbouillon bildet, im Gegensatz zum Immunserum, worin das Wachsthum in Form zusammengeballter, am Boden des Gefässes unterhalb einer klaren Flüssigkeitsschicht liegender Bakterienhaufen statt hat.

Wir begegnen damit auch beim Pneumococcus dem bereits bei den verschiedenen Bakterienarten bekannten und heutzutage in der Bakteriologie eine grosse Rolle spielenden $\mathrm{Phänomen} \mathrm{der} \mathrm{Agglutination.}$

1 Metschnikoff, Annales de l'Institut Pasteur. T. V. p. 474.

${ }^{2}$ Bezançon et Griffon, Ebenda. T. XIV. p. 444.

${ }^{3}$ Pane, Riforma med. 1897-1898. - Centralblatt f. Bakteriologie. Bd. XXI. S. 664 .

- Huber, Centralblatt für innere Medicin. 1902. Nr. 17.

${ }^{5}$ Neufeld, Diese Zeitschrift. Bd. XL. S. 54. 
Und zwar finden wir diese Agglutination den genannten Autoren zufolge sowohl bei dem in Fällen menschlicher Pneumonie von selbst entstehenden, als bei dem durch Infection geeigneter Thiere künstlich erzeugten Immunserum. Doch liegen hier nach den bisherigen Untersuchungen die Verhältnisse wesentlich anders, als wie es uns z. B. von dem bekanntesten und ältesten Object des Agglutinationsphänomens, nämlich vom Typhusbacillus her geläufig ist. Denn während das letztgenannte Bacterium von jedem unverdünnten Normalserum agglutinirt zu werden pflegt und sogar bei menschlichem Serum ein Agglutinationswerth von 1:20 bis 1:30 noch als normal angesehen wird, fanden alle bisherigen Beobachter beim Pneumococcus die Agglutinationsgrenze nicht etwa eines normalen, sondern eines Immunserums wesentlich niedriger liegend, d. h. bei Verdünnungsgraden, deren Wirksamkeit man beim Typhus noch im Bereich oder wenigstens an der Grenze des Normalen liegend anzusehen gewöhnt ist, ja manche der genannten Untersucher konnten sogar nur bei Anwendung unverdünnten Immunserums Agglutinationserscheinungen auslösen.

Der höchste Werth ist bisher beim menschlichen Serum, und zwar bei pneumoniekranken Kindern durch Jehle ${ }^{1}$ vor nicht langer Zeit gefunden worden. Dieser Werth betrug 1:160. Erheblich geringer war die Agglutinationsfähigkeit der von Neufeld" antersuchten menschlichen und Thiersera, von denen bereits ein im Verhältniss von 1:60 agglutinirendes als stark wirkend bezeichnet wird. Darnach kommen die von Bezançon und Griffon ${ }^{3}$ durch Immunisirung von Kaninchen erhaltenen Werthe von 1:50, und noch geringer sind die von $\mathrm{Pane}^{4}$ ) angegebenen, der bei Eselserum ein Verhältniss von 1:30,. Kuhserum aber bei 1:25 und Kaninchenserum nur bei 1:15 aggiutinirend fand. Ueber das Verhalten von menschlichem Serum liegen aus neuester Zeit noch Angaben von Gargano und Fattori ${ }^{5}$ vor, welche im Gegensatz zu den höheren Werthen Jehle's nur eine Agglutination von 1:10 feststellen konnten. - Ein anderes Moment, welches das Agglutinationsphänomen beim Pneumococcus von dem uns bei dem Typhusbacillus bekannten unterscheidet, ist die zu seiner Auslösung nöthige Zeitdauer. Während man nämlich bei diesem gewöhnt ist, mit einem schnellen Eintreten der Agglutination zu rechnen und für praktische Zwecke eine Einwirkung von $1 / 2$ bis 2 Stunden bei Brüttemperatur als Grenze des Versuches an-

1 Jehle, Wiener klin. Wochenschrift. 1903. Nr. 32.

2 Neufeld, Diese Zeitschrift. Bd. XL. S. 54.

${ }^{3}$ Bezançon et Griffon, Société d. Biol. Juin. 5. - Sem. méd. p. 217.

4 Pane, Centralblatt für Bakteriologie. Bd. XXI. S. 664 .

- Gargano e Fattori, Rivista critica di clinica med. 1903. Nr. 12-15. 
zunehmen pflegt, haben es die bisherigen Untersucher für nöthig gefunden, das Wachsthum des Pneumococcus in dem betreffenden Serum, d. h. einen Zeitraum von 15 bis 24 Stunden abzuwarten. Bezançon und Griffon ${ }^{1}$ sagen in einer ihrer Arbeiten ausdrücklich, dass die bei Typhus übliche Widalsche Technik beim Pneumococcus nicht anwendbar sei, sondern in der eben angegebenen Weise verfahren werden müsse.

Mit Rücksicht auf diese Angaben haben wir uns zunächst derselben Versuchsanwendung bedient und den Pneumococcus in normalem und Immunserum sich selbst überlassen. Dabei stellte sich denn zunächst heraus, dass, wie von genannten Forschern richtig beobachtet worden war, die Pneumokokken im Allgemeinen im uurerdünnten Immunserum agglutinirt wurden, während sie von normalem Serum nicht weiter beeinflusst wurden, sondern sich gleichmässig darin entwickelten. Indessen ändern sich diese Verhältnisse sofort, wenn man statt des Kaninchenserums, an welchem die erwähnten Beobachtungen gemacht worden waren, ein stärker wirkendes Serum, nämlich Hammelserum anwendet. Dann kann man die Agglutination in der geschilderten Weise auch bei normalem Serum, und zwar nicht bloss in nur unverdünntem Zustande, sondern sogar noch in Verdünnungen ziemlich hohen Grades eintreten sehen; der Unterschied zwischen normalem und Immunserum ist also auch für den Pneumococcus kein absoluter, sondern - wie bei Typhus - nur ein gradueller.

Der mikroskopische Befund, welchem das geschilderte makroskopische Aussehen bei positiver Agglutination entspricht, war eine deutlich vermehrte Neigung des Pneumococeus zur Kettenbildung, wie dies schon Metschnikoff erkannt hatte, wogegen man bei gleichmässiger Trübung des Serums genau wie in einer Bouilloncultur nur einzelne Diplokokken antraf. Dieser Unterschied kam sogar bei denjenigen unserer Stämme zum Ausdruck, welche, wie in dem ersten Capitel erwähnt, ein besonders ausgebildetes Kettenwachsthum von vornherein zeigten, denn bei solchen Stämmen wurden die Ketten in agglutinirtem Zustande der Bakterien noch länger und verschlungener. Indessen sei zugegeben, dass sich, wie Bezançon und Griffon ${ }^{2}$ behaupten, das Auftreten der Agglutination mikroskopisch bei den Stämmen ohne Kettenbildung besser beurtheilen lässt. Man konnte dann unter dem Mikroskop deutlich verfolgen, wie die einzelnen Diplokokken zu Ketten zusammentraten und diese Ketten sịch dann kreuzweis über einander S. 41.

1 Bezançon et Griffon. Ref. Baumgarten's Jahresbericht. 1900. Bd. XVI.

${ }^{2}$ Bezançon et Griffon, Annales de l'Institut.Pasteur. T. XIV. p. 449. 
lagerten, bis dass aus etwa je 12 bis 15 solcher Ketten eigenthümliche und charakteristische sternförmige Figuren entstanden. Beim weiteren Fortschreiten des Agglutinationsphänomens traten dann immer mehr Ketten hinzu, so dass schliesslich aus den eben beschriebenen Sternbildungen unförmige Klumpen entstanden, wie sie als Ausdruck der Agglutination von den früheren Beobachtern, die nur dieses Endstadium gesehen hatten, beschrieben worden sind.

Dieses Einhergehen makroskopischer und mikroskopischer Erscheinungen sahen wir indessen nicht bei jedem Agglutinationsversuch, selbst bei Verwendung unverdünnten Immunserums auftreten. Bezançon und Griffon führen diese Thatsache bereits an und Huber spricht von einer Art unvollkommener Agglutination, welche zwar mikroskopisch wahrgenommen werden konnte, makroskopisch jedoch die gleichmässige Trübung des Serums nicht veränderte. Es sei an dieser Stelle bereits bemerkt, dass auch wir einer solchen Erscheinung in unseren Versuchen begegneten, dieselbe aber niemals als positiven Ausfall berücksichtigten, sondern als solchen nur die deutlich mikroskopisch und makroskopisch wahrnehmbare Agglutination gelten liessen. Die Ursache des verschiedenen Ausfalles der Agglutinationsprüfung; auch bei Verwendung unverdünnten Immunserums, findet sich in der Arbeit von Bezançon und Griffon bereits angedeutet. Diese beiden Forscher bemerkten nämlich, dass mitunter menschliches Serum nur mit den von demselben Krankheitsfalle stammenden Pneumokokken, hingegen nicht mit den in ihrem Laboratorium vorhandenen Culturen Agglutination gab, eine Erscheinung, die übrigens Gargano und Fattori in ähnlicher Weise wahrgenommen haben. Bezançon und Griffon wurden durch diese Beobachtung zu der Annahme veranlasst, dass es möglicher Weise rerschiedene Varietäten des Pneumococcus geben könne, deren Unterscheidung allein durch das Agglutinationsverfahren möglich sei. Dieser Spur sind wir nun gemäss unseren, zu Beginn der Arbeit auseinandergesetzten Absichten nachgegangen und haben eine grössere Anzahl von thierischen Immunseris auf entsprechend viele Pneumokokkenstämme einwirken lassen. Eine Gruppe solcher Versuche wurde zunächst mit dem Serum immunisirter Kaninchen angestellt. Zum Zweck der Immunisirung bewährte sich folgende Methode: Die Thiere erhielten 6 bis 7, durch einstündiges Erhitzen auf $60^{\circ}$ abgetödtete und in Bouillon (oder steriler Kochsalzlösung) aufgeschwemmte Agarculturen es war dies die höchste ohne Schaden für die Thiere anwendbare Einzelgabe - in einer Sitzung in die Ohrvenen eingespritzt. Dann wurde nach 8 bis 10 Tagen aus der Carotis steril Blut entnommen und das so gewonnene Serum zu Versuchen benützt. Eine Lösung von Blut- 
farbstoff im Serum, welche beim Absetzen zuweilen vorkommt, störte die Agglutinationsversuche durchaus nicht, wie andere Autoren angeben, wenn es anch natürlich angenehmer ist, mit einem klaren Serum zu arbeiten. Von dem so gewonnenen Serum wurden Verdünnungen mit steriler Kochsalzlösung zunächst $\overline{a \vec{a}}$, davon $1 \mathrm{zu} 10$ hergestellt und in ihrer Wirksamkeit gegenüber einer Reihe von Pneumokokkenstämmen geprüft. Dabei stellte sich nun heraus, dass die Anzahl der beeinflussten Stämme bei Verdünnung $\overline{a \vec{a}}$ partes geringer war, als bei Verwendung des unverdünnten Serums, und bei Verdünnung von 1 zu 10 geringer als bei $\overline{a \bar{a}}$ partes, wobei jedoch ausdrücklich herrorgehoben sei, dass bei den Stämmen, die der Agglutination überhaupt zugänglich waren, die Deutlichkeit der Erscheinung nichts zu wünschen übrig liess. Diese Beobachtung veranlasste uns, zu einem noch höheren Grade der Verdünnung überzugehen und trotz der gegentheiligen Angabe Bezançon's und Griffon's die Widal'sche Technik zur Anwendung zu bringen. Dieselbe bewährte sich denn auch vollkommen, so dass meines Erachtens kein Grund besteht, zur Agglutination von Pneumokokken andere Methoden als die sonst übliche zu benutzen. Im Einzelnen gestaltete sich die Ausführung in der Weise, dass wir unsere Proben gleich nach der Ansetzung des Versuches und von da ab nach Aufenthalt derselben im Brütschrank in kurzen Zwischenräumen mikroskopisch auf das Eintreten der bereits ausführlich beschriebenen Agglutinationserscheinungen controlirten. Diese pllegten sich bei Verwendung unverdünnten Serums und bei Verdünnungen von $\bar{a} \bar{a}$ partes im Verlauf einer halben Stunde, bei Verdünnungen höheren Grades innerbalb 3 bis. 4 Stunden, einzustellen, und nach noch längerer Zeit, nämlich 12 bis 15 Stunden war dann die Reaktion auch makroskopisch deutlich, und nur solche Versuche, bei denen die Reaction bis zu diesem Grade verfolgt werden konnte, liessen wir, wie bereits erwähnt, als positive gelten. Waren bei Verdünnung des Serums auf 1 zu 10 nur sehr wenige Stämme der Agglutination zugänglich befunden worden, so blieb, wenn wir noch höhere Grade der Verdünnung anwandten, immer nur ein einziger Stamm übrig, und zwar alle Mal derjenige, mittels dessen die Immunisirung der betreffenden Thiere erfolgt war. Es entspricht diese Beobachtung den bereits angeführten Bezançon's und Griffon's sowie ferner Gargaro's und Fattori's, die bei menschlicher Pneumonie das Serum gegenüber dem von demselben Kranken stammenden Pneumococcus am wirksamsten fanden. Dieser sogenannte homologe Stamm erwies sich in unseren Versuchen mit thierischen Immunseris der Agglutination regelmässig in so hohem Grade zugänglich, dass wir Verdünnungen des Serums anwenden konnten, wie sie bei 
Agglutinationsrersuchen mit Pneumokokken überhaupt noch niemals erreicht worden sind. Die folgenden Tabellen, aus welchen das Ergebniss unserer Agglutinationsversuche mit Kaninchenserum bis zu einer Verdūnnung von 1 bis 1000 zu ersehen ist, mögen diese Verhältnisse erläutern.

Versuchs-Serie Nr. I.

A. Kaninchenserum.

Serum I.

\begin{tabular}{|c|c|c|c|c|c|c|c|c|c|}
\hline Cultur & 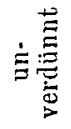 & $=$ & $\stackrel{9}{=}$ & $=$ & $\stackrel{8}{=}$ & $\stackrel{8}{2}$ & $\stackrel{\circ}{\circ}$ & $\stackrel{\circ}{\stackrel{\circ}{-}}$ & $\begin{array}{l}\frac{0}{0} \\
\text { 营 } \\
0\end{array}$ \\
\hline$I$ & + & + & + & + & + & + & + & - & - \\
\hline II & + & + & + & - & - & - & - & - & - \\
\hline III & + & + & - & - & - & - & - & - & - \\
\hline IV & + & + & + & - & - & - & - & - & - \\
\hline $\mathrm{V}$ & + & + & - & - & - & - & - & - & - \\
\hline VI & - & - & - & $\ldots$ & - & - & - & - & - \\
\hline VII & + & + & -- & - & - & - & - & - & - \\
\hline VIII & + & + & - & - & - & - & - & - & - \\
\hline IX & + & - & - & - & - & - & - & - & - \\
\hline \multicolumn{10}{|c|}{ Serum II. } \\
\hline$I$ & + & + & + & - & - & - & - & - & - \\
\hline II & + & + & + & + & + & + & - & - & - \\
\hline III & + & + & - & - & - & - & - & - & - \\
\hline IV & + & - & - & - & - & - & - & - & - \\
\hline $\mathrm{V}$ & + & - & - & - & - & - & - & - & - \\
\hline $\mathrm{VI}$ & - & - & - & - & - & - & - & - & - \\
\hline VII & + & + & - & $\ldots$ & - & - & - & - & - \\
\hline VIII & + & + & + & - & - & - & - & - & - \\
\hline IX & + & - & - & - & - & - & - & - & - \\
\hline
\end{tabular}

Serum III.

\begin{tabular}{r||c|c|c|c|c|c|c|c||c} 
I & - & - & - & - & - & - & - & - & - \\
II & + & - & - & - & - & - & - & - & - \\
III & + & + & + & + & + & + & + & + & - \\
IV & + & + & - & - & - & - & - & - & - \\
V & + & - & - & - & - & - & - & - & - \\
VI & + & - & - & - & - & - & - & - & - \\
VII & - & - & - & - & - & - & - & - & - \\
VIII & + & + & - & - & - & - & - & - & -
\end{tabular}


Serum IV.

\begin{tabular}{|c|c|c|c|c|c|c|c|c|c|}
\hline Cultur & 宵葛 & $\stackrel{*}{=}$ & $=$ & $\stackrel{\circ}{=}$ & $\stackrel{\circ}{=}$ & $\stackrel{\circ}{=}$ & $\stackrel{\circ}{\circ}$ & $\stackrel{\circ}{\circ}$ & 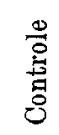 \\
\hline I & + & + & - & - & - & - & - & - & - \\
\hline II & + & - & - & - & - & - & - & - & - \\
\hline III & + & - & - & - & - & - & - & - & - \\
\hline IV & + & + & + & + & + & + & + & + & - \\
\hline $\mathrm{V}$ & + & + & - & - & - & - & - & - & - \\
\hline VI & + & - & - & - & - & - & - & - & - \\
\hline VII & + & - & - & - & - & - & - & - & - \\
\hline VIII & + & + & - & - & - & - & - & - & - \\
\hline IX & + & + & - & - & - & - & - & - & - \\
\hline
\end{tabular}

Serum VIII.

\begin{tabular}{r||c|c|c|c|c|c|c|c||c} 
I & + & + & - & - & - & - & - & - & - \\
II & + & - & - & - & - & - & - & - & - \\
III & + & + & + & - & - & - & - & - & - \\
IV & + & + & - & - & - & - & - & - & - \\
V & + & + & - & - & - & - & - & - & - \\
VI & - & - & - & - & - & - & - & - & - \\
VII & + & - & - & - & - & - & - & - & - \\
VIII & + & + & + & + & + & + & + & - & $=$ \\
IX & + & - & - & - & - & - & - & - & -
\end{tabular}

Stamm I, II aus normalem Speichel,

, III, IV, V, VI ans pneumonischem Sputum,

, VII aus tuberculösem Sputum,

" VIII aus Eiter von einer Otitis media.

" IX aus panophthalmitischem Secret.

Noch schärfer ersichtlich wurden diese so weit festgestellten Thatsachen, als wir dazu "übergingen, von Thieren mit einem von Natur stärker wirksamen Serum, nämlich von Schafen, ein Immunserum zu gewinnen. $\mathrm{Zu}$ diesem Zwecke wurden zwei kräftige und gesunde Schafe im Gewicht von etwa 70 Pfund in folgender Weise immunisirt. Sie erhielten zuerst in's Unterhautzellgewebe Einspritzungen von Bouillonculturen, die durch einstündiges Erhitzen auf $60^{\circ} \mathrm{C}$. abgetödtet waren, später lebende Agarculturen, von kleinen Dosen ansteigend. Die Thiere reagirten auf jede Gabe mit einer Temperatursteigerung von ungefähr $1^{\circ}$, die in einem Tage vorüberging. Die Einspritzungen wurden in Zwischenräumen von 14 Tagen wiederholt, so dass der Zeitraum der Immunisirung sich über mehrere Monate hin erstreckte. Wenn die Thiere 2 bis 4 Massenculturen vertragen konnten, wurde die Immunisierung für abgeschlossen erachtet, und es sei noch ausdrücklich bemerkt, 
dass beide Thiere sich während der ganzen Immunisirungszeit bei vollk $0 \mathrm{mmener} \mathrm{Gesundheit} \mathrm{befanden.} \mathrm{Einige} \mathrm{Tage} \mathrm{nach} \mathrm{vollendeter}$ Immunisirung erfolgte die Entnahme von Blut durch einen Troikart aus der Vena jugularis externa. Die Versuche mit diesem Serum wurden in derselben Weise, wie mit dem Kaninchenserum angestellt. Im Gegensatz zu letzterem wirkte, wie bereits erwähnt, schon das normale Hammelserum - von denselben Thieren vor der Impfung entnommen - auf die Pneumokokken stark agglutinirend, und zwar erwiesen sich bei einer Verdünnung $\overline{\alpha \bar{a}}$ partes und $1 \mathrm{zu} 10$ fast alle Pneumokokkenstämme der Agglutination zugänglich, während bei weiteren Verdünnungen die Zahl der beeinflussten Stämme proportional dem Grade der Verdünnung abnahm. Doch wurden durch das eine unserer beiden Hammeisera zwei Pneumokokkenstämme noch bis zu einer Verdünnung von 1 zu 250 angegriffen; wir begegnen damit also einer Wirkung normalen Serums, die alle bisher von Immunseris erreichten Werthe übertrifft. Durch die Immunisirung wurde naturgemäss die ohnehin schon so hohe Agglutinationskraft dieser Sera noch erheblich gesteigert, doch gingen mit der Steigerung auch Veränderungen der agglutinirenden Eigenschaft des Serums Hand in Hand; es war nämlich die Agglutinationskraft des Immunserums gegenüber den Pneumokokken im Allgemeinen unter die des normalen Serums herabgesunken. Gegenüber dem zur Immunisirung verwendeten Stamme jedoch hatte sich wiederum eine Specificität ausgebildet, welche in der Wirksamkeit ron Verdünnungen so hohen Grades zum Ausdruck kam, wie sie bisher überhaupt nur bei hochwirksamem Typhus- und Choleraserum beobachtet worden ist. Die Agglutinationsgrenze betrug nämlich bei einem unserer Thiere $1 \mathrm{zu} 5000$ und bei dem anderen, welches eine längere und auch höhere Immunisirung durchgemacht hatte, 1 zu 100000, wofür die nachstehende Tabelle, aus welcher gleichzeitig auch der Rüchgang der allgemeinen Agglutinationskraft gegenüber der des Normalserums $\mathrm{zu}$ ersehen ist, als Beleg dienen möge.

\section{B. Hammelserum.}

Normalserum.

\begin{tabular}{|c|c|c|c|c|c|c|c|c|c|c|c|c|c|}
\hline 总 & 字葛 & 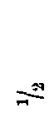 & $\stackrel{2}{\Rightarrow}$ & $\stackrel{8}{\pi}$ & 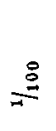 & 总 & 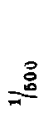 & $\frac{1}{0}$ & 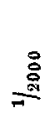 & $\frac{\vdots}{\circ}$ & $\stackrel{\Xi}{\stackrel{\Xi}{+}}$ & 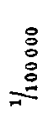 & 营. \\
\hline $\begin{array}{r}\text { II } \\
\text { II }\end{array}$ & + & + & + & $\begin{array}{l}+ \\
+\end{array}$ & + & $=$ & - & $=$ & - & - & $\bar{I}$ & - & - \\
\hline III & + & + & + & + & + & + & - & - & - & - & - & - & 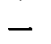 \\
\hline IV & + & + & + & + & + & - & - & - & - & - & - & - & - \\
\hline $\mathrm{V}$ & + & + & + & + & + & - & - & - & - & - & - & - & 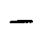 \\
\hline
\end{tabular}


Normalserum. (Fortsetzung.)

\begin{tabular}{|c|c|c|c|c|c|c|c|c|c|c|c|c|c|}
\hline 串 & 葛蓄 & $\stackrel{x x}{=}$ & $\stackrel{9}{=}$ & $\stackrel{\circ}{=}$ & $\stackrel{\&}{\rightleftarrows}$ & 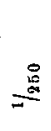 & $\stackrel{\circ}{=}$ & $\stackrel{8}{\circ}$ & 离 & $\begin{array}{r}: \\
= \\
=\end{array}$ & 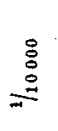 & $\stackrel{\circ}{\stackrel{0}{0}}$ & 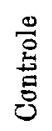 \\
\hline VI & + & - & - & - & - & - & - & - & - & - & - & - & - \\
\hline VII & + & + & + & 6 & + & + & - & - & - & - & - & - & - \\
\hline VIII & + & + & + & + & - & - & - & - & - & - & - & - & - \\
\hline IX & + & + & + & + & - & - & - & - & - & - & - & - & - \\
\hline
\end{tabular}

Immunserum III.

\begin{tabular}{r|r|l|l|l|l|l|l|l|l|l|l|l|l} 
I & + & + & + & + & - & - & - & - & - & - & - & - & - \\
II & + & + & - & - & - & - & - & - & - & - & - & - & - \\
III & + & + & + & + & + & + & + & + & + & + & + & + & - \\
IV & + & + & + & - & - & - & - & - & - & - & - & - & - \\
V & + & + & - & - & - & - & - & - & - & - & - & - & - \\
VI & + & + & + & - & - & - & - & - & - & - & - & - & - \\
VII & + & + & + & - & - & - & - & - & - & - & - & - & - \\
VIII & + & + & - & - & - & - & - & - & - & - & - & - & - \\
IX & + & + & + & - & - & - & - & - & - & - & - & - & -
\end{tabular}

Stamm I, II aus normalem Speichel,

" III, IV, V, VI aus pneumonischem Sputum,

"VII aus tuberculösem Sputum,

" VIII aus Otitis media-Eiter,

" IX aus Panophtalmitissecret.

Versuchs-Serie Nr. II.

A. Kaninchenserum.

Serum A.

\begin{tabular}{|c|c|c|c|c|c|c|c|c|c|}
\hline Cultur & 香苟 & $=$ & $\cong$ & $\stackrel{8}{2}$ & $\stackrel{8}{=}$ & $\stackrel{\circ}{=}$ & $\stackrel{\circ}{\circ}$ & $\frac{\mathrm{g}}{\mathrm{g}}$ & 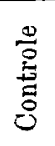 \\
\hline A. & + & + & + & + & + & + & + & + & - \\
\hline B. & + & + & + & + & - & - & - & - & - \\
\hline C. & - & - & - & - & - & - & - & - & - \\
\hline D. & + & + & - & - & - & - & - & - & - \\
\hline E. & + & - & - & - & - & - & - & - & - \\
\hline F. & + & - & - & - & - & - & - & - & - \\
\hline G. & + & + & + & - & - & - & - & - & - \\
\hline
\end{tabular}


Dre Pneudororken.

Serum B.

\begin{tabular}{|c|c|c|c|c|c|c|c|c|c|}
\hline Cultur & 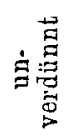 & $\Rightarrow$ & $=$ & $\stackrel{8}{=}$ & $\stackrel{8}{=}$ & $\stackrel{\circ}{=}$ & $\stackrel{\circ}{=}$ & $\stackrel{\check{E}}{=}$ & \\
\hline A. & + & + & + & - & - & - & - & - & \\
\hline B. & + & + & + & + & + & - & - & - & \\
\hline C. & + & - & - & - & - & - & - & - & \\
\hline D. & + & - & - & - & - & - & - & - & \\
\hline E. & + & + & - & - & - & - & - & - & - \\
\hline F. & + & + & - & - & - & - & - & - & - \\
\hline G. & + & - & - & - & - & - & - & - & \\
\hline \multicolumn{10}{|c|}{ Serum C. } \\
\hline A. & + & + & - & - & - & - & - & - & - \\
\hline B. & + & - & - & - & - & - & - & - & - \\
\hline c. & + & + & + & - & - & - & - & - & - \\
\hline D. & + & - & - & - & - & - & - & - & - \\
\hline E. & + & + & - & - & - & - & - & - & - \\
\hline F. & + & - & - & - & - & - & - & - & - \\
\hline G. & + & - & - & - & - & - & - & - & - \\
\hline \multicolumn{10}{|c|}{ Serum D. } \\
\hline A. & + & - & - & - & - & - & - & - & - \\
\hline $\begin{array}{l}\text { B. } \\
\text { C. }\end{array}$ & $\bar{t}$ & - & - & $\overline{-}$ & $\overline{-}$ & - & $\overline{-}$ & - & - \\
\hline D. & + & + & + & + & + & + & + & $\bar{t}$ & - \\
\hline $\mathrm{E}$. & + & + & + & - & - & - & - & - & - \\
\hline F. & + & - & - & - & - & - & - & - & - \\
\hline G. & + & + & - & - & - & - & - & - & - \\
\hline
\end{tabular}

Serum E.

\begin{tabular}{l|l|l|l|l|l|l|l|l||l} 
A. & + & - & - & - & - & - & - & - & - \\
B. & + & + & - & - & - & - & - & - & $=$ \\
C. & - & - & - & - & - & - & - & - & - \\
D. & + & + & + & - & - & - & - & - & - \\
E. & + & + & \pm & \pm & + & \pm & + & + & - \\
F. & + & + & - & - & - & - & - & - & $=$ \\
G. & + & - & - & - & - & - & - & - & -
\end{tabular} Serum F.
A.

+
+
+
+
+
+
\begin{tabular}{l|c|c}
- & - & - \\
+ & + & $=$ \\
+ & - & - \\
+ & - & - \\
+ & + & +
\end{tabular}
G. + +
Zeitschr. f. Hggiene. LI.
\begin{tabular}{l|l|l|l|l||l}
- & - & - & - & - & - \\
- & - & - & - & - & - \\
- & - & - & - & - & - \\
- & - & - & - & - & - \\
+ & + & \pm & - & - & - \\
- & - & - & - & - & -
\end{tabular} 
Serum G.

\begin{tabular}{|c|c|c|c|c|c|c|c|c|c|}
\hline Cultur & 它葛 & $\Rightarrow$ & $\stackrel{9}{=}$ & $\stackrel{\text { 总 }}{=1}$ & $\stackrel{8}{=}$ & $\stackrel{8}{\circ}$ & 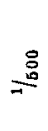 & $\stackrel{\circ}{=}$ & $\begin{array}{l}\text { 总 } \\
\text { 营 }\end{array}$ \\
\hline A. & + & + & - & - & - & - & - & - & - \\
\hline B. & + & + & - & - & - & - & - & - & - \\
\hline C. & - & - & - & - & - & - & - & - & - \\
\hline D. & + & - & - & - & - & - & - & - & - \\
\hline E. & + & - & - & - & - & - & - & - & - \\
\hline F. & + & + & - & - & - & - & - & - & - \\
\hline G. & + & + & + & + & + & + & + & + & - \\
\hline
\end{tabular}

Stamm A., B., C. aus tuberculösem Sputum,

„ D., E. aus normalem Speichel,

" F., G. aus pneumonischem Sputum.

\section{B. Hammelserum.}

Normalserum.

\begin{tabular}{|c|c|c|c|c|c|c|c|c|c|c|c|c|c|}
\hline 壱 & 岂: & $=$ & $\stackrel{0}{=}$ & $\frac{8}{7}$ & $\frac{8}{-1}$ & $\frac{\circ}{\stackrel{\circ}{*}}$ & $\frac{\circ}{\circ}$ & $\frac{\Xi}{=}$ & 总 & $\stackrel{\stackrel{8}{8}}{=}$ & $\stackrel{\circ}{\stackrel{\circ}{=}}$ & $\stackrel{\circ}{\circ}$ & 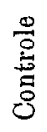 \\
\hline A. & + & + & + & + & - & - & - & - & - & - & - & - & - \\
\hline B. & + & + & + & + & + & + & - & - & - & - & - & - & - \\
\hline C. & + & + & + & - & - & - & - & - & - & - & - & - & - \\
\hline D. & + & + & + & - & - & - & - & - & - & - & - & - & - \\
\hline E. & + & + & + & + & + & + & - & - & - & - & - & - & - \\
\hline $\mathrm{F}$. & + & + & + & + & + & - & - & - & - & - & - & - & - \\
\hline G. & + & + & + & + & + & - & - & - & - & - & - & - & - \\
\hline
\end{tabular}

Immunserum $G$.

\begin{tabular}{l||l|l|l|l|l|l|l|l|l|l|l|l|l} 
A. & + & + & + & - & - & - & - & - & - & - & - & - & - \\
B. & + & + & + & - & - & - & - & - & - & - & - & - & - \\
C. & + & - & - & - & - & - & - & - & - & - & - & - & - \\
D. & + & + & + & - & - & - & - & - & - & - & - & - & - \\
E. & + & - & - & - & - & - & - & - & - & - & - & - & - \\
F. & + & + & + & + & - & - & - & - & - & - & - & - & - \\
G. & + & + & + & + & + & + & + & + & + & + & - & - & -
\end{tabular} Stamm A., B., C. ans tuberculösem Spatum,

"D., E. aus normalem Speichel,

" F., G. aus pnenmonischem Sputum. 
Die Frage nach der

\section{Immunität}

gegen den Pneumococcus haben wir bereits bei der Behandlung der Agglutination gestreift, da die Immunisirung sonst gegen den Pneumococcus empfänglicher Thiere nöthig war, um die agglutinirenden Sera zu erhalten. Da wir aber in dem Serum auch die Träger der immunisirenden Kräfte zu sehen gelernt haben, so ist es wohl nicht unberechtigt, wenn wir gemäss dem im Eingang des vorigen Capitels Gesagten auch die Lehre von der Immunität zu den der modernen Forschung angehörigen Abschnitten rechnen, wiewohl es an Untersuchungen über die Möglichkeit einer Immunisirung gegen den Pneumococcus überhaupt schon bei den ältesten Forschern nicht gefehlt hat. Hat doch bereits A. Fränke ${ }^{1}$ im Jahre 1886 festgestellt, dass ein Thier, welches eine Pneumokokkeninfection überstanden hat, dadurch gegen die Wirkung grösserer Dosen geschützt ist, eine Wahrnehmung, die noch in demselben Jahre von Foà und Bordoni-Uffreduzzi ${ }^{2}$ bestätigt wurde. Erst später, nämlich im Jahre 1891, gelang es Emmerich und Fawitzky ${ }^{3}$, sodann Foì und Carbone ${ }^{4}$, mit dem Serum immunisirter Thiere andere Thiere gegen die Pneumokokkeninfection zu schützen. Daraufhin bat es nicht an Versuchen ge- fehlt, derartiges Immunserum bei Fällen menschlicher Pneumonie anzuwenden. Zuerst waren es G. und F. Klemperer ${ }^{5}$, dann vor Allem Washbourn ${ }^{6}$ unter Verwendung ron Pferde- und Pane ${ }^{7}$ unter Verwendung von Eselserum, die behaupteten, ein für Menschen wirksames Heilserum gefunden zu haben; doch hat bis jetzt keines der Pneumokokkensera die darauf gesetzten Hoffnungen erfüllt. Daher ist die Zahl der Forscher, die sich eine Immunisirung gegen den Pneumococcus zur Aufgabe gesetzt haben, auffallend gross und entsprechend auch die Zahl der bierfür angegebenen mehr oder minder complicirten Methoden. Von allen diesen hat sich nur die alteste und einfachste, die schon von den beiden erstgenannten Beobachtern hier angewandt wurde, Eingang verschafft und sich bis zum heutigen Tage erbalten. Wir meinen damit das Verfahren, den Thiereu erst durch Hitze abgetödtete oder abgeschwächte und erst später lebende vollvirulente Culturen in

${ }^{\perp}$ A. Fränkel, Zeitschrift für klin. Medicin. 1886.

${ }^{2}$ Foà e Bordoni-Uffreduzzi, Deutsche med. Wochenschrift. 1886.

${ }^{3}$ Emmerich and Fawitzky, Münchener med. Woehenschrift. 1891.

+ Foà e Carbone, Gaz. med. di Torino. 1891. - Riforma med. 1891.

s G. u. F. Klemperer, Berliner klin. Wochenschrift. 1891.

${ }^{8}$ Washbourn, Brit. med. Journ. 1897.

' N. Pane, Riforma medica. 1897-1898. - Centralblatt für Bakteriologie. Bd. XXI. S. 664 . 
steigender Dosis subcutan einzuspritzen. Mittelst dieser Methode, deren sich namhafte Forscher, wie Kruse und Pansini ${ }^{1}$, die beiden Klemperer ${ }^{2}$, Lery und Steinmetz, Mennes ${ }^{4}$, Issaeff ${ }^{5}$ und insbesondere Washbourn bedient haben, ist es uns gelungen, die beiden im vorigen Capitel besprochenen hochwerthigen Schafsera zu gewinnen. Auf dieselbe Weise gelang es uns, Kaninchen so weit zu immunisiren, dass sie die Einspritzung einer ganzen virulenten Agarcultur vertragen konnten. Indessen hat dieses Verfahren gerade bei Kaninchen den grossen Nachtheil, dass es sich über längere Zeiträume (bis mehrere Monate) hin erstreckt und Jeder, der mit Kaninchen gearbeitet hat, weiss, wie leicht diese Thiere verheerenden Seuchen ausgesetzt sind und wie schwer es ist, immunisirte Exemplare mehrere Monate lang lebend und gesund zu erhalten. Daher leistete uns eine in neuerer Zeit viel geübte Methode, da sie in kürzester Zeit die Gewinnung brauchbarer Immunsera ermöglicht, gute Dienste. Dieselbe besteht in einer einmaligen intravenösen Einverleibung einer grösseren Menge abgetödteter Cultur. Das den Thieren nach 8 bis 10 Tagen entnommene Serum besass die im vorigen Capitel besprochenen und tabellarisch wiedergegebenen hohen agglutinirenden Eigenschaften. Die Schutzwirkung dieser Sera wurde nicht untersucht. Für diese Zwecke diente uns allein das Schafserum, nachdem wir vor. der Immunisirung dieser Thiere festgestellt batten, dass das normale Schafserum - ebenso wie übrigens auch das normale Kaninchenserum - jeder Schutzwirkung völlig entbehrte. Als empfängliches Versuchsthier benutzten wir für diese Untersuchungen weisse Mäuse, weil man mit solchen Thieren am leichtesten grössere Versuchsreihen ansetzen kann. Und zwar umfasste eine solche jedes Mal 16 Mäuse, die folgender Versuchsanordnung ausgesetzt wurden:

\section{Einverleibung Yron Serum.}

\begin{tabular}{c|c|c|c}
17 Stunden & 2 Stunden & zu gleicher Zeit & 2 Stunden nach \\
vor der Impfung & vor der Impfung & mit der Impfung & der Impfung
\end{tabular}

Jede dieser Gruppen betraf 3 Stück und bei jeder wurde ein viertes inficirtes Thier ohne Serumbehandlung als Controlthier belassen.

Die Impfung erfolgte intraperitoneal, die Einverleibung des Serums unter die Haut.

${ }^{1}$ Kruse und $\mathrm{P}_{\mathrm{ansini}}$, Diese Zeitschrift. 1892. Bd. XI.

" Klemperex, Berliner klin. Wochenschrift. 1891.

${ }^{3}$ Levy und Steinmetz, Archiv für experim. Pathol. 1896. Bd. XXXVII.

${ }^{4}$ Mennes, Diese Zeitschrift. 1897. Bd. XXV.

' Issaeff, Annales de l'Institut Pasteur. 1893. 
Die Menge des Impfmaterials betrug jedes Mal $1 / 100$ Oese einer 24 stündigen Bouilloncultur, entsprechend dem 20000 fachen der geringsten tödtlichen Dosis $(=1 / 2000000)$ des betreffenden Stammes.

Die beigegebene Serummenge betrug je $1 / 2,1 / 10$ und $1 / 100 \mathrm{~cm}$ bei einer der 3 Mäuse.

Das Ergebniss dieser Versuche war folgendes:

Mit Immunserum vor der Infection (gleichviel ob 17 oder 2 Stunden) behandelte Mäuse kamen stets durch.

Mit Immunserum gleichzeitig mit der Infection behandelte Mäuse kamen meist durch.

Mit Immunserum nach der Infection behandelte MIäuse erlagen meist.

Die unbehandelten Controlthiere erlagen stets.

Hierzu sei ausdrücklich bemerkt, dass sich das Immunserum nur dann in der eben erwähnten Weise als wirksam erwies, wenn die Impfung der Versuchsthiere mit demselben Pneumokokkenstamme erfolgte, mittels dessen das Immunserum erzeugt worden war, und dass es jedem anderen Stamme gegenüber sich ebenso unwirksam wie normales Hammelserum zeigte.

Dieses Verhalten der immunisirenden Eigenschaften unseres Serums entsprach also genau der im vorigen Capitel festgestellten Specificität der agglutinirenden Fähigkeit, die cbenfalls immer nur gegenüber dem zur Gewinnung des Serums verwendeten Stamme (dem sogenannten homologen), diesem gegenüber jedoch in auffallend hoher Wirksamkeit nachgewiesen worden war.

Durch diese Ergebnisse wird es erklärlich, weshalb sich noch keines der durch die verschiedenen Methoden gewonnenen "Immunsera" in der Praxis bewährt hat. Jedoch bleibt für dieses Ziel noch ein Weg zu beschreiten übrig, den Tavel bei der Gewinnung des Streptokokkenserums, wie es scheint, mit Erfolg eingeschlagen hat, nämlich die Immunisirung mit möglichst vielen Stämmen, die Erzeugung eines sogenannten polyvalenten Serums.

Einen Versuch nach dieser Richtung zu machen hatte ursprünglich auch in unserer Absicht gelegen, indessen haben uns äussere Gründe zur Aufgabe dieser Absicht gezwungen und es muss späteren Bearbeitern dieser Frage überlassen bleiben, auf dem angegebenen Wege nach Erfolgen zu suchen. ${ }^{1}$

${ }^{1}$ Inzwischen ist ein nach den Angaben von $R_{0} e m e r$ hergestelltes polyvalentes Serum von der Firma Merck in Darmstadt in Handel gebracht worden. 
Anhangsweise sei hier noch einer eigenthümlichen, ron Neufeld ${ }^{1}$ zur Immunisirung ron Kaninchen angegebenen Methode gedacht, die wir ebenfalls in den Bereich unserer Untersuchungen gezogen haben. Der genannte Forscher giebt nämlich an, dass die normale Gallenflüssigkeit von Kaninchen in hohem Maasse die Gabe besitzt, die Pneumokoklen aufzulösen und dass die so gewonnene klare Flüssigkeit ein hervorragendes Mittel zur Immunisirung von Thieren derselben Art darstelle. Indessen giebt Neufeld selbst bereits zu, dass es Pneumokokkenstämme geben könne, die diesem Auflösungsprocess nicht unterliegen.

Wir hatten mit dieser Methode gar kein Glück: von unseren Stämmen wurde keiner durch die Galle beeinflusst, sie entwickelten sich im Gegentheil darin sehr üppig, so dass die Flüssigkeit trüb wurde und erwiesen sich bei Aussaat auf Agar im Gegensatz zu den Angaben Neufeld's als lebensfähig.

\section{Zusammenfassendes Ergebniss.}

Neuere Arbeiten über den Pneumococcus, über welche in der Einleitung berichtet worden ist, haven es bereits in hohem Grade wahrscheinlich gemacht, dass wir in dem Fränkel-Weichselbaum'schen Diplococcus nicht ein bestimmtes Bacterium, sondern eine Vielheit nahe verwandter Mikroorganismen vor uns haben. Für diese Vermuthung haben wir durch die schon im Beginn unserer Untersuchungen erfolgte Auffindung eines aus menschlicher Pneumonie gezüchteten Diplococcus, der sich durch die Gabe, Gelatine zu verflüssigen, von allen bisher bekannten Pneumokokken unterschied, in seinen sonstigen Eigenschaften jedoch in koiner Weise ron deren bekanntem Typus abwich, rascher als wir vermutheten, eine neue Stütze gefunden. Im Uebrigen wiesen die von uns untersuchten Stämme in ihrer Morphologie, Cultur, Pathogenität und Virulenz zwar Unterschiede auf, indessen nicht grössere, als wir sie auch bei anderen Bakterien, die wir deswegen doch für etwas Einheitliches ansehen müssen, zu finden gewöhnt sind. Hingegen hat uns die systematische Untersuchung der Beziehungen zwischen Bakterien und Serum mittels des Immunisirungs- und besonders des Agglutinationsverfahrens mit Sicherheit gezeigt, dass die Verbältnisse bei den Pneumokokken genau denen bei den Streptokokken, mit denen sie ja ohnehin als nahe verwandt $z u$ betrachten sind, entsprechen. Zwar sind Unterschiede der Agglutination verschiedener Stämme durch Immunserum auch beim Typhusbacillus gefunden worden ${ }^{2}$, allein diese

' Neufeld, Diese Zeitschrift. Bd. XXXIV. S. 454.

: Laubenbeimer, Dissertation. Giessen 1903. 
Unterschiede sind doch nur graduelle und äussern sich keineswegs im Sinne einer specifischen Beeinflussung des zur Immunisirung verwendeten Stammes. Daher wird es gewiss auch Niemand einfallen, den Begriff des Typhusbacillus in eine Vielbeit auflösen zu wollen, was natürlich mit der Abtrennung des Paratyphus, auf dessen Verhältnisse hier einzugehen sich erübrigt, nichts zu thun hat. Bei den Streptokokken - bei den Staphylokokken passt der Vergleich nicht, weil hier die Unterschiede viel deutlicher zu Tage liegen - hat man sich aber schon längst daran gewöhnt, diese Bakterien trotz völliger äusserlicher Vebereinstimmung für eine Vielheit von Arten anzusehen und hat aus dieser Anschauung durch die Gewinnung polyvalenter Sera schon längst praktische Consequenzen gezogen. Ausserdem ist die Richtigkeit dieser Auffassung erst ganz neuerdings durch eine Arbeit von Fi scher ${ }^{1}$ aus dem Ta vel'schen Institut ebenfalls mit Hülfe des Agglutinationsverfahrens endgültig bewiesen worden. Ebensolche Beweiskraft dürfen wir aber auch wohl für die in vorstehender Arbeit veröffentlichten Agglutinations- und Immunisirungsversuche in Anspruch nehmen und man wird sich daher gewöhnen müssen, von jetzt ab nicht mehr von dem „Pneumoccocus“, sondern von den "Pneumokokken", ebenso wie von den "Streptokokken" zu sprechen. $\mathrm{Ob}$ es freilich gelingen wird, auch in diesem Falle der veränderten Anschauung praktische und für die Therapie nutzbare Consequenzen abzugewimnen, muss die Zukunft lehren.

\section{Schlusssätze.}

1. Die dem Typus des Fränkel-Weichselbaum'schen Pneumococcus entsprechenden Bakterien können morphologische Unterschiede aufweisen. Dieselben äussern sich meist in der Richtung überwiegender Grösse, aber auch in ausserordentlicher Kleinheit der Individuen.

2. In den culturellen Eigenschaften herrscht zwischen den einzelnen Stämmen grosse Uebereinstimmung. Nur ein sonst typischer und virulenter Stamm unterschied sich durch seine Fähigkeit, Gelatine zu verflüssigen, auffallend von allen anderen. Alle Pneumokokken gedeihen am besten bei schwach alkalischer Reaction. Für praktische Zwecke ist das altbewährte Glycerinagar allen complicirten Nährböden vorzuziehen.

3. Die Virulen $z$ der Pneumokokken unterliegt grossen Schwankungen. Am virulentesten pflegen die Pneumonie-Pneumokokken zu sein, doch giebt es hierron Ausnahmen.

\footnotetext{
${ }^{1}$ Fischer, Centralblatt für Bakteriologie. Bd. XXXVII.
} 
Die höchste von uns - und bisher überhaupt - beobachtete Virulenz betrug $1 / 2000000$ Oese einer 24 stündigen Bouilloncultur (entsprechend 5 Colonieen) für weisse Mäuse.

Speichelkokken besitzen eine constantere Virulenz mittleren Grades.

Avirulent sind meist Stämme aus alten Eiterherden (Abscessen, Empyem).

Zur Erhaltung der Virulenz ist öftere Umzüchtang und Thierpassage nothwendig; doch gelang es uns auf diese Weise ohne Zuhülfenahme besonderer Methoden den grössten Theil unserer Stämme über ein Jahr lang lebend und virulent zu erhalten.

4. Pathogen kann der Pneumococcus für weisse Mäuse, Kaninchen, Meerschweinchen und im Gegensatz zu früheren Beobachtungen auch für Tauben sein. In der Art der Pathogenität weisen die einzelnen Stämme Unterschiede auf. Der Tod der Versuchsthiere erfolgte durch Septicämie.

5. Die Agglutination ist eine specifische für den Stamm, mittelst dessen das agglutinirende Serum erzeugt ist. Dies gilt sowohl für Kaninchen-, wie für das stärker wirksame Schafserum. Der Grad der Agglutination kann ein sehr hoher sein (1:1000 bei Kaninchen-, $1: 100000$ bei Schafserum.)

Für die Anstellung der Agglutination eignet sich zunächst die Widal'sche Technik. Nach 24 Stunden ist die Agglutination bei positivem Ausfall auch makroskopisch erkennbar.

6. Es gelingt active und passive Immunisirung gegen den Pneumococcus; doch ist auch die Immunisirung für den dazu benützten Stamm streng specifisch.

7. Die Pneumokokken sind eine Vielheit verwandter Bakterien, ebenso wie die Streptokokken. 